\title{
Review
}

Tom Lindström* and Folke Österberg

\section{Evolution of biobased and nanotechnology packaging - a review}

https://doi.org/10.1515/npprj-2020-0042

Received May 7, 2020; accepted August 24, 2020; previously published online September 11, 2020

\begin{abstract}
This review deals with the evolution of bio-based packaging and the emergence of various nanotechnologies for primary food packaging. The end-of life issues of packaging is discussed and particularly the environmental problems associated with microplastics in the marine environment, which serve as a vector for the assimilation of persistent organic pollutants in the oceans and are transported into the food chain via marine and wild life. The use of biodegradable polymers has been a primary route to alleviate these environmental problems, but for various reasons the market has not developed at a sufficient pace that would cope with the mentioned environmental issues. Currently, the biodegradable plastics only constitute a small fraction of the fossil-based plastic market. Fossil-based plastics are, however, indispensable for food safety and minimization of food waste, and are not only cheap, but has generally more suitable mechanical and barrier properties compared to biodegradable polymers. More recently, various nanotechnologies such as the use of nanoclays, nanocellulose, layer-by-layer technologies and polyelectrolyte complexes have emerged as viable technologies to make oxygen and water vapor barriers suitable for food packaging. These technological developments are highlighted as well as issues like biodegradation, recycling, legislation issues and safety and toxicity of these nanotechnologies.
\end{abstract}

Keywords: biobased; food packaging; microplastics; nanocellulose; nanotechnology; polyelectrolyte complexes; review.

\footnotetext{
*Corresponding author: Tom Lindström, Division of Fibre Technology, Department of Fibre and Polymer Technology, KTH Royal Institute of Technology, Teknikringen 58, SE-100 44 Stockholm, Sweden; and Department of Chemistry, SUNY Stony Brook, 100 Nicolls Road, 104 Chemistry, Stony Brook, USA, e-mail: toml@kth.se

Folke Österberg, Mid Sweden University, FSCN, SE-85170 Sundsvall, Sweden, e-mail: folke.osterberg@gmail.com
}

\section{Introduction}

Synthetic polymer plastic materials are manufactured and designed to various needs to mankind in the global economy. The largest use segment of synthetic plastics is in various packaging applications. Whereas sustainable paper and board materials are indispensable for secondary and tertiary packaging, synthetic polymers are needed in food and electronic packaging because the necessity to create barriers to oxygen and water vapor. Such barriers are necessary for food packaging both to get fresh food and avoid infections and various diseases and to delay food spoilage and, hence, avoid food waste. Total yearly world production of synthetic polymers 2016 was currently 335 million tonnes and these polymers are predominantly based on fossil resources. Thus, there is a great challenge to replace fossil resources with renewable materials. Synthetic polymers are primarily designed to meet performance and durability and not for recyclability and degradability, which has resulted in a strong growth of disposed polymers on both land and in marine environments. The current waste disposable systems are landfilling, incineration, composting and mechanical recycling. The vast majority of plastic waste $(40 \%)$ finds its way into landfills, $25 \%$ is incinerated, while another $22 \%$ is unmanaged dumps and rejected in recycling (Degan and Shinde 2019). Landfilling will destroy the soil quality and is a disaster for the marine fauna, whereas incineration of used plastic requires extensive cleaning of flue gases. Mechanical recycling has been a temporary recovery but the volumes are generally too small. Composting is a viable technology, ignoring the material waste and economics, but is also depending on the efficiency of the biodegradation. Hence, the major strategy during the past decades has been to use biodegradable polymers such as poly(lactide), polybutylene succinate, polyalkanoates etc. and various natural biopolymers from plants, wooden materials, seaweeds etc.

There is a rich number of scientific approaches to develop biodegradable materials and many excellent reviews in this area, to which a few reviews such as Delidovich 
et al. (2016), Galbis et al. (2016), Gandini et al. (2016), Schneiderman and Hillmyer (2017) can be suggested.

The substitution of fossil plastics with biodegradable materials in all different areas of food packaging remains difficult given the broad spectrum of functionality offered by fossil-based polymers. In addition to their high water sensitivity, the properties of biodegradable polymers make them economically uncompetitive in comparison with those of conventional plastic polymers, particularly regarding their limited barrier properties. This remains an ultimate technical challenge in this field.

Apart from the developments of biodegradable polymers and natural biopolymers there is the demand of the circular economy approach to sustainable polymers namely the chemical recyclable polymers (Hong and Chen 2017, MacArthur and McKinsey 2017, 2019).

An interesting recent paper has also discussed such a circular economy approach to poly(lactide) (Payne et al. 2019).

This contribution intends to review the most available biodegradable polymers and discuss the most popular approaches to develop food packaging materials during the past decades. It is also recognized that, there are extensive general reviews of bio-based packaging that has recently been published, e.g., Helanto et al. (2019). Whereas, there is a long story of biodegradable polymers, particularly in the food packaging segment of edible packaging, the market for bioplastics (except edible packaging) is still very small compared to fossil-based plastics. During the latest two decades, there has also been a focus on various nanotechnologies, like nanocellulose and nanoclay composites, and layer-by layer (Lbl) technologies together with polyelectrolyte complexes, which have added a niche of interesting developments, albeit the fact that nanotechnology has its own various issues such as toxicity, legislation issues and customer suspicion.

Our ambition has been to provide a comprehensive view of major bioplastics and nanotechnologies and also including the field of plastic problems in the marine environment, end-of life issues of plastics (recycling, legislative issues, safety issues) under current focus today.

The choice of selecting food packaging is that this is the field of packaging that has an immense complexity and is the largest field of packaging materials and also the most need of developments because of the need of sustainability packaging and the current environmental issues.

\section{Biodegradation of plastics in compost, soil and marine environments}

Composting is a process in which the organic matter is converted to $\mathrm{CO}_{2}$ and a soil-like material (humus) by a mixed group of microorganisms (Emadian et al. 2017, Kale et al. 2007, Leja and Lewandowicz 2010, Zeng et al. 2016). The use of compost as a microbial community for biodegradation has been extensively studied for both bio-based and fossil based bioplastics including polymers such as poly(lactide), poly(hydroxyalkanoate), poly(caprolactones) and various starch-based blends etc. and it is generally found that under the right $\mathrm{pH}$, moisture and temperature conditions they are all susceptible to biodegradation. There is a wide difference between home composting (low temperature) and industrial composting (high temperature type $50-70^{\circ} \mathrm{C}$ ). Many polymers, like poly(lactide), degrades very slow in home composting because degradation occurs primarily by hydrolysis and not by microbial attack, resulting in a slow degradation rate (Hong and Chen 2017).

The degradation of fossil based plastics results in very little mineralization (conversion into biomass, $\mathrm{CO}_{2}, \mathrm{H}_{2} \mathrm{O}$ or $\mathrm{CH}_{4}$ ) which has been reported, e. g. Wei and Zimmermann (2017). The largest volume plastics, polyethylene terephthalate, which has hydrolysable bonds is more susceptible to biodegradation than polyethylene, polystyrene and polypropylene, but is still classified as not being biodegradable.

Soil environments contain a vast number of microorganisms, which enable degradation of plastics to be more feasible than in other environments like water and air. Generally, soils are very different depending on their composition (microorganisms, $\mathrm{pH}$, temperature, moisture etc.), but it is expected that lower temperatures, a higher crystallinity of the polymer will decrease the biodegradation rate.

Poly(lactide) is a major bioplastic and has several packaging application areas, has high crystallinity and has desirable properties for the packaging segment, but higher temperatures are required for biodegradation as in industrial composting. Whereas, microorganisms and enzymes are known to degrade polylactic acid (PLA) nonenzymatic hydrolysis is the major degradation mechanism for PLA. It has been observed (Narancic and O'Connor 2019) that there is a very slow degradation, taking over three decades, for PLA in soils. By using certain blends between PLA and other biocompostable polymers, and using a smart design, possibilities could open up for faster 
biodegradation. It can be concluded that biodegradable plastics must be managed, and biodegradable plastics cannot be seen as a solution for the current plastic pollution problems (Narancic and O'Connor 2019, Narancic et al. 2018, Scaffaro et al. 2019, Yin and Yang 2020).

There has been a major focus in society for the endof-life management of biodegradable plastics using industrial composting, but another option is anaerobic gasification, and this option have also been investigated with various bioplastics with successful results (Narancic et al. 2018).

Plastic makes up about 80 to $85 \%$ of marine litter (Auta et al. 2017) and this constitutes a major problem.

In general, the plastic waste is consigned to landfills. However, large amounts end up as marine debris as a result of insufficient treatment capacity, accidental inputs, littering, illegal dumping and coastal human activities. It's calculated that 275 million metric tons (MT) of plastic waste was generated in 192 coastal countries in 2010, with 4.8-12.7 million MT entering the ocean, which is approximately $60-80 \%$ of the marine litter (Jambeck et al. 2015).

Although the defined size of these microparticles has varied between different studies over the past decade, the National Oceanic and Atmospheric Administration (NOAA) now defines the term "microplastic" as fragments smaller than $5 \mathrm{~mm}$ in diameter (Horton et al. 2017). In the marine environment, microplastics can be generated from primary sources and enter directly into the environment as plastic pellets that were used as raw material in the plastic industry and/or in hygiene and personal care products (Cole et al. 2011). They may also enter indirectly from secondary sources (e.g. food packaging), such as fragments and fibres obtained from the fragmentation of larger plastic debris.

Microplastics are easily taken for zooplankton, a common food source for the marine environment, and therefore end up in stomachs of various marine organisms. Hence, through direct and indirect ingestion of microplastics, it ends up in the marine food chain. This is critical as hydrophobic plastics tend to adsorb hydrophobic organic pollutants such as polychlorinated biphenyls (PCBs) and polycyclic aromatic hydrocarbons (PAHs) to a very high extent (Tanaka et al. 2020, Yeo et al. 2019). Hence, microplastics can serve as a vector for the assimilation of persistent organic pollutants and heavy metals by marine organisms in the environment.

As indicated before, the degradation of plastics in marine environments, is different and there are, at least, three important degradation mechanism for plastics in oceans
(Min et al. 2020). Firstly, bacteria colonize the surface (depending on the surface energy) of plastics and have a propensity for biofilm formation and this provides an opportunity for biodegradation in the form of mass loss via surface erosion. There are many bacteria and microbial enzymes that facilitate surface erosion. Typical rates for these processes decrease as follows:

$$
\text { polyesters }>\text { polyamides }>\text { polyolefins }
$$

Secondly, abiotic hydrolysis of functional groups, like esters, which reduce the molecular weight $\left(M_{w}\right)$ of polymers, thereby making polymers susceptible to disintegration. This process is facilitated by the alkalinity of seawater $(\mathrm{pH}$ ranges from 8 to 8.3). Generally, the abiotic and biotic processes proceed slowly and depend on a number of factors such as type of functional group, $M_{w}$, surface to volume ratio etc.

Finally, the exposure of ultraviolet (UV) radiation and oxygen causes photodegradation and results in a decrease in $M_{w}$ and cracking that facilitates the formation of microplastics.

This is the theory, but practical experiments regarding the fate of biodegradable polymers in freshwater and seawater has concluded that even after more than a year, there is very little degradation of polymers classified as biodegradable polymers. The authors tested these biodegradable polymers: Polycaprolactone (PCL), polylactic acid (PLA), Poly(3-hydroxybutyrate) (PHB) and poly(lactic-co-glycolic acid) (PLGA) and it was only PLGA that was degraded within a year. Neither was there any difference between the degradation in freshwater and seawater (Bagheri et al. 2017). This fact should be considered in the following text, where we follow the standard classification of biodegradable polymers.

\section{Recycling}

A wide range of technologies are currently used for waste pre-treatment and sorting. These range from manual dismantling and picking to automated processes such as shredding, sieving, air or liquid density separation, magnetic separation, and highly sophisticated spectrophotometric sorting technologies such as UV/visible spectroscopy (VIS), near infrared (NIR), Laser, etc. (www. plasticseurope.org).

Plastic fractions contained in complex waste streams may not be easily enough sortable. In such cases, alternative recovery solutions exist, such as feedstock/chemical recycling or recovery of the calorific value of the plastic waste to substitute conventional fuels. 
Mechanical recycling of plastics refers to the processing of plastics waste into secondary raw material or products without significantly changing the chemical structure of the material. The difficulty of plastic sorting logistics, washing and drying before the secondary melt processing also leads to thermomechanical degradation due to high operating temperatures resulting in deterioration of the polymer properties.

These problems associated with the recycling and degradation of synthetic plastics also motivates the development of biobased, degradable materials.

The concept of a circular economy suggests that chemical recovery may be a viable route. An end-of-life (EOL) analysis suggests that chemical recovery has several interesting options (Hong and Chen 2017, McKeown et al. 2019, Payne et al. 2019). For instance, the conversion of PLA to LA has by the US Department of Energy been identified as a future platform chemical with its plethora of commodity chemicals.

\section{Legislative actions}

The first comprehensive piece of EU legislation on packaging waste entered into force in 1994 with Directive 94/62 EC on Packaging and Packaging Waste (PPWD). The directive deals with the problems of packaging waste and setting targets for recovery and recycling (eur-lex.europa.eu, document 31994L0062). Recently the EU Green Deal Policy (European commission, Brussels 11.12.2019) was taken. Strategies for inter alia plastics waste published are the Circular Economy 2.0 (March 11, 2020) and the Industrial Strategy (March 10, 2020). The circular economy addresses all plastics packaging placed on the EU market, either as reusable, or to be recycled in a cost-efficient way by 2030 . Further, more than $50 \%$ of the plastic waste is to be recycled and $55 \%$ recycled content is required in plastic packagings. Microplastics are specifically addressed with restrictions, developing labelling, standardisation and regulatory measures on unintentional release. The Commission will address sustainability challenges on sourcing, labelling and use of bio-based plastics and the use of biodegradable plastics (eur-lex.europa.eu, document 52020DC0098).

The industrial strategy taken is directed towards requirements for sustainable products, obligation to sustainable environmental claims through standard approaches. Essential is also to foster new markets for climate-neutral and circular products, having a transparency towards consumers about carbon and environmental footprints (ec.europa.eu March 10, 2020).
The single use plastic (SUP) directive was proposed 2018 which is a part of the EU plastic strategy in a circular economy. The main objectives are to phase out "unnecessary" single use plastics and reduce consumption, production and introduce incentives towards reusable systems. The SUP directive will be effective earliest mid-2021. The SUP directive is taken into account in many European countries by plastic bags bans. In the proposal it is voluntary to determine reduction targets and offer alternative products within each country, which has given rise to differences in enforcement.

Also, world-wide actions to ban plastic bags usage have been introduced in 74 countries with varying degrees of enforcement and in 37 countries a charge per bag has been taken. Expanded polystyrene (EPS) is also banned in many countries (The Swedish government official investigations 2018:84).

\section{Food packaging demands}

Different foods have different demands on packaging. Table 1 shows the maximum gain of oxygen to maintain the freshness and the maximum water gain or loss. There are many quality factors for foods such as colour, oxidation, microbiology, structure, flavour, enzymatic degradation, photooxidation and chemical changes such as hydrolysis, protein denaturation, cross-linking etc. This means that food packaging has a very high complexity in developing the optimum packaging strategy for various foods. Certain examples are given below to show the complexity for the demand of various foods, see also a very good early review by Petersen et al. (1999). Exposure to oxygen can cause deterioration of colours, aromas, vitamins and induce oxidation. These foods benefit from packaging that can maintain a vacuum/nitrogen that will provide a barrier to oxygen. Fresh meat, poultry, pasta products benefit from environments that can maintain either a vacuum or a targeted concentration of oxygen and high concentration of carbon dioxide to prevent oxidation or microbial growth. Fresh meat can be the subject of enzymatic, microbial and physical changes and demand a high oxygen concentration by using modified atmospheric packaging (MAP) with oxygen contents of $70-80 \% \mathrm{O}_{2}$ and $20-$ $30 \% \mathrm{CO}_{2}$. Cured meat on the other hand can be subject to $\mathrm{NO} / \mathrm{NaCl}$, which changes the pigment to nitrosylmyoglobin, which is sensitive to photooxidation demanding a minimized $\mathrm{O}_{2}$-content.

Seafood is subjected to autolysis caused by intrinsic enzymes, metabolic activity by microorganisms and oxida- 
Table 1: Approximate critical amounts of oxygen and moisture that foods can stand in order to maintain fresh. Adapted from Robertson (2006).

\begin{tabular}{lrr}
\hline Food or beverage & Maximum oxygen gain (ppm) & Maximum water gain or loss \\
\hline Canned milk, vegetables and fresh foods & $1-5$ & $3 \%$ loss \\
Wines and beer & $1-5$ & $3 \%$ loss \\
Instant coffee & $1-5$ & $2 \%$ gain \\
Canned fruits & $5-15$ & $3 \%$ loss \\
Dried foods & $5-15$ & $1 \%$ gain \\
Nuts and snacks & $5-15$ & $5 \%$ gain \\
Fruit juices and carbonated drinks & $10-40$ & $3 \%$ loss \\
Oils and salad dressings & $50-200$ & $10 \%$ gain \\
Jellies, syrups, pickles, olives and vinegar & $50-200$ & $3 \%$ loss \\
Liquors & $50-200$ & $3 \%$ loss \\
Condiments & $50-200$ & $1 \%$ gain \\
Peanut butter & $50-200$ & $10 \%$ gain \\
\hline
\end{tabular}

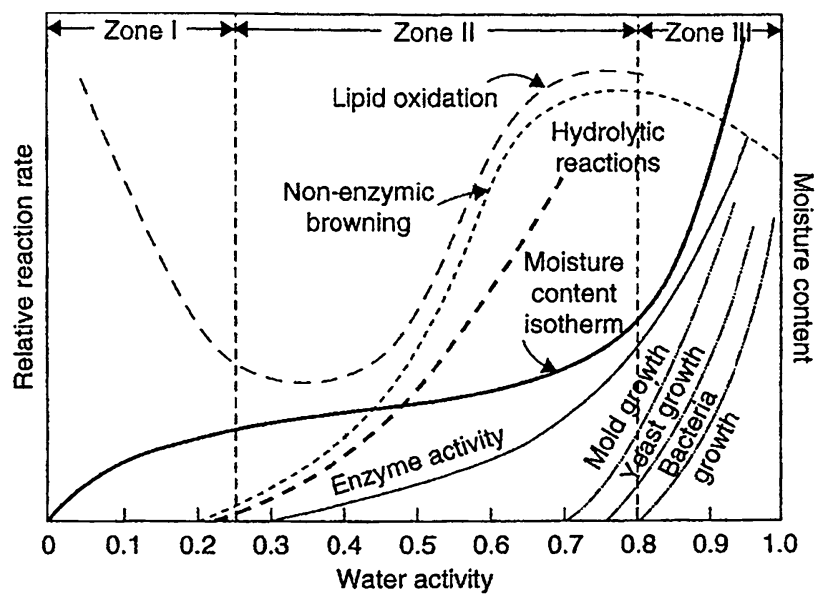

Figure 1: Relationship between food water activity and moisture content and the relative rates for a number of chemical reactions, enzyme activities and microorganism growth that lead to food deterioration (Kester and Fennema 1986, Krochta 2006).

tion. High fat fish demands low oxygen contents in order to avoid oxidation and a moderate water vapor barrier is also demanded. Breads, cakes, crackers and chocolate demand a high moisture barrier and a low oxygen barrier to avoid oxidation of fatty products. Fruits and vegetables are living organisms requiring $\mathrm{O}_{2}$ and produce $\mathrm{CO}_{2}$. Optimum $\mathrm{RH}$ is $85-95 \%$ for fruits and $90-98 \%$ for vegetables. For cheeses, $\mathrm{MAP}$ with $\mathrm{N}_{2}$ or $\mathrm{CO}_{2}$ replacing $\mathrm{O}_{2}$ is recommended etc. (Krochta 2006, Robertson 2006, 2009).

The water activity affects the food quality in a number of different ways. Figure 1 shows the relative reaction rate of lipid oxidation, non-enzymatic browning, hydrolytic reactions, enzyme activity, mould, yeast and bacterial growth. Interestingly, a too low water activity allows an increased oxidation of lipids, whereas in zone II oxi- dation decreases, but tend to increase in the bulk zone III. In conclusion, the barrier properties (the oxygen and water vapour permeability) are the key properties in the design of food packaging materials. There are many reviews on applications of bioplastics for food packaging, e. g., Jiménez et al. (2012), Lagarón et al. (2016), Peelman et al. (2013).

\section{Food packaging materials}

A comparison of bio-based polymers relatively to synthetic polymers with respect to their oxygen transmission rate and water vapour transmittance is given in Figure 2. From Figure 2, the following conclusions can be made:

- The superior performance of ethylene vinyl alcohol (EVOH) in the oxygen transmission rate (OTR) cannot be met by PLA or polyhydroxyalkanoates (PHA).

- As far as the water vapor transmittance (WVT) is concerned, the PHA is close to low-density polyethene (LDPE).

- Neither PLA or PHA are good gas barriers.

- Polyvinylidene chloride is the only polymer with both an excellent gas barrier and water vapour barrier.

The interplay between the polymer chemistry and the permeability is extremely important for the packaging industry see, e.g., Koros (1990), Lagarón et al. (2004), Miller and Krochta (1997). The type of substituent groups on a polymer can have a very large effect on the permeability coefficient governed by the tightness/adhesion of polymer chains (cohesive energy density) and the free volume of the molecules in a polymer. An increased cohesive energy density is reflected by a higher polarity 

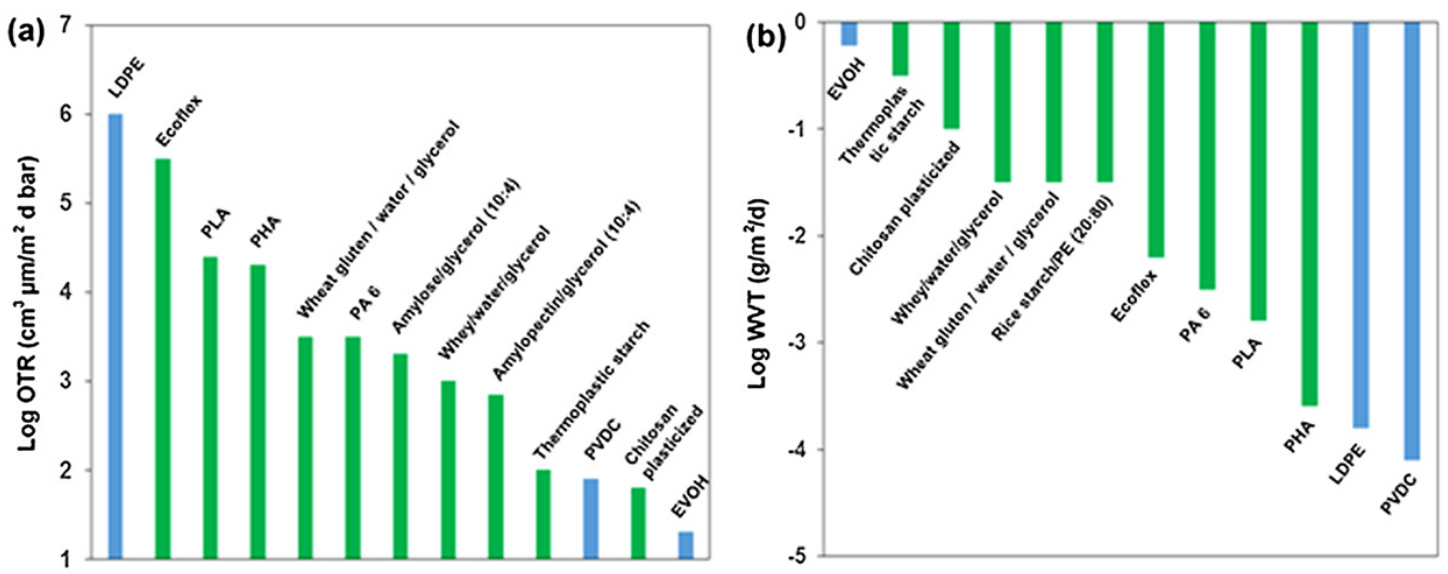

Figure 2: Barrier properties of some bio-based materials versus foil-based packaging materials. a) oxygen transmission rate; b) water vapour transmittance (Rastogi and Samyn 2015).

of the polymer chains. Cellulose has a very high cohesive energy density due to the tight network of hydrogen bonds and the free volume of a TEMPO-treated (2,2,6,6-tetramethylpiperidine-1-oxyl) nanocellulose has also been determined (Fukuzumi et al. 2011).

It should be considered that there are many nanocoatings, that were developed in the mid 1980s, such as thin glass-like $\mathrm{SiO}_{x}$ produced by physical or chemical vapour deposition and many other inorganic coatings such as nano-silver particles, nano-zink oxide, titanium nitride etc. An early excellent review on such commercial technologies has been published (Lange and Wyser 2003) and also later reviews, e. g., Bumbudsanpharoke and Ko (2015), Rossi et al. (2017), but will not be of concern in this context.

\section{Bioplastics}

The term bioplastics was coined by the European Bioplastics 2016 and there are some confusions about of the world "bioplastic". Bioplastics are defined as biodegradable, biobased or both. A material coordinate for bioplastics is given in Figure 3. Hence there are four different groups of plastics:

- One group that refer to classical plastics that are not biodegradable and made from fossil based polymers, such as polyethylene, polystyrene etc.

- A second group is plastics made from biomass feedstock and are biodegradable. Examples in this group are cellulose, starches and polyesters such as PLA and PHA.

- A third group are biodegradable plastics from fossil resources. Examples in this group are polycaprolactone
(PCL), polybutylene succinate (PBS) and poly(butylene adipate-co-terephthalate) (PBAT).

- The fourth group is non-biodegradable plastics that are produced from biomass. Example are biopolyethylene (PE), produced from bioethanol fuel produced from sugar cane.

The current global production of bioplastics was around 2,1 million tonnes 2019 (European Bioplastics) and is expected to rise to 2.4 million tonnes around 2024 (Figure 4). the non-biodegradable part accounts for $45 \%$, whereas the biodegradable part accounts for $55 \%$. The total capacity of biodegradable polymers is therefore very small compared to fossil-based plastics. The largest part of the biodegradable polymers are the various starch blends and PBAT manufactured by BASF (Ecoflex®).

\section{Poly (lactic acid)}

PLA is a well-known biobased plastic that has attracted immense attention over the past few decades (Auras et al. 2011, Castro-Aguirre et al. 2016, Garlotta 2002, Rabnawaz et al. 2017) and has enjoyed many reviews. PLA is commercially synthesized via ring opening polymerization via lactides in a two-step process. In nature, lactides predominantly exist as the L-lactide isomer along with a few $\%$ of its D-lactide isomer. Some selected properties of PLA are shown in Table 2 together with the properties of PHA polypropylene (PP) and poly (ethylene terephthalate) (PET).

Commercial PLA for the packaging industry generally has a L-lactide content in excess of $92 \%$. The higher the L-lactide content, the higher is the crystallinity and at a 


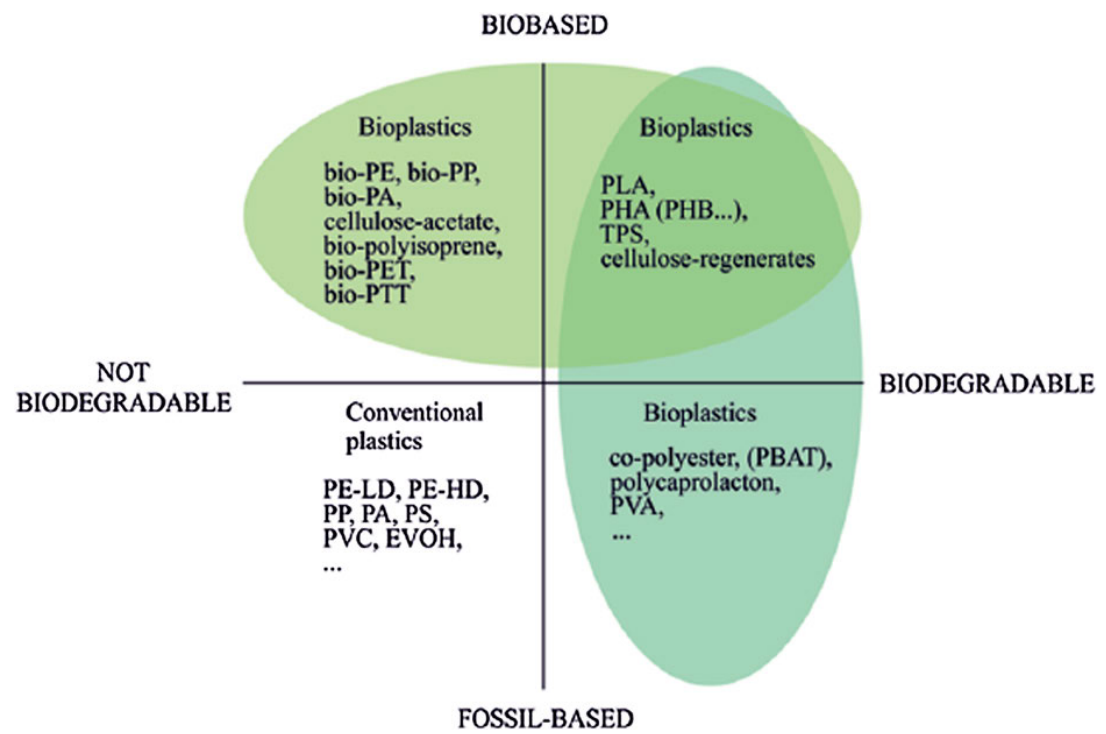

Figure 3: Material coordinate system of bioplastics: EVOH: ethylene vinyl alcohol; PA: polyamide; PBAT: polybuthylene adipate terephthalate; PE: polyethylene; PE-HD: high density polyethylene; PE-LD: low density polyethylene; PET: poly(ethylene terephthalate); PHA: polyhydroxyalkanoate; PHB: polyhydroxybutyrate; PLA: polylactic acid; PP: polypropylene; PS: polystyrene; PTT: polytrimethylene terephthalate; PVA: polyvinyl alcohol; PVC: polyvinyl chloride; TPS: thermoplastic starch. Adopted from Rujnić-Sokele and Pilipović (2017).

Global production capacities of bioplastics 2024 (by material type)

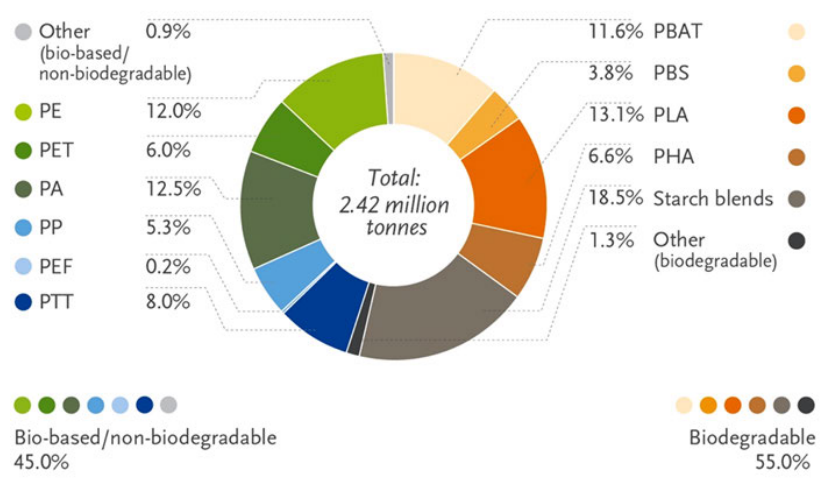

Source: European Bioplastics, nova-Institute (2019)

More information: www.european-bioplastics.org/market and www.bio-based.eu/markets

Figure 4: The projected global production of bioplastics 2024 (European Plastics).

higher content of D-lactide, PLA becomes amorphous and, hence, deteriorating the barrier properties. Interestingly, in contrast to proteins and polysaccharides the oxygen permeability of PLA decreases with a higher relative humidity, possibly because water blocks the pathway through which oxygen diffuses through the plastic. PLA has, however, a poor barrier for water vapor. Compared to $\mathrm{PP}$, the water barrier performance of PLA is only $10 \%$ of the barrier performance of PP. PLA has 2-3 times higher modulus than
PP and the tensile strength is higher than for PHAs. Manufacturing of PLA-plastic does not create any problems and blow moulding, extrusion and thermoforming can be conducted similar to other thermoplastics. Typical applications of PLA are in compost bags, food packaging, and disposable tableware.

There are numerous manufacturers of PLA, see, e.g., lists in Armentano et al. (2013), Castro-Aguirre et al. (2016), Scaffaro et al. (2016). There is an extensive number of PLA/polysaccharide composites reported, see, e. g., Scaffaro et al. (2016) as well as reviews on nanostructured PLA and polyester materials, see, e. g., Armentano et al. (2013), Bordes et al. (2009).

\section{Polyhydroxyalkanoate}

PHAs are promising polyesters produced by bacteria through aerobic fermentation of various carbon sources. (Anjum etal. 2016, Rabnawaz etal. 2017, Samori et al. 2015). PHAs can also be prepared synthetically. The simplest member of the PHA-family is poly(hydroxybutanolate) (PHB), which is prepared via a fermentative approach. Bacteria-based PHB is isotactic (repeating conformic), whereas PHBs that are prepared from butyrolactone are atactic (non conformic) with a lower melting point.

Important is that the large majority of current biodegradable polymers can only biodegrade under very 
Table 2: Selected properties of various polyesters and polypropylene (PP). Abbreviations: polyhydroxyalkanoate (PHA), polylactic acid(PLA), poly (ethylene terephthalate) (PET), Water vapour transmitance (WVTR). Adapted from Rabnawaz et al. (2017).

\begin{tabular}{lrrrr}
\hline Property (units) & PHAs & PLA & PP & PET \\
\hline$T_{g}\left({ }^{\circ} \mathrm{C}\right)$ & 2 & 66 & -10 & $73-80$ \\
$T_{m}\left({ }^{\circ} \mathrm{C}\right)$ & $160-175$ & 141 & $160-175$ & $245-265$ \\
Modulus (GPa) & $1-2$ & $2.3-2.8$ & $1.1-1.5$ & $2.7-4.1$ \\
Tensile strength (MPa) & $15-40$ & $74-82$ & $31-42$ & $48.2-72.3$ \\
Elongation at break (\%) & $1-15$ & $78-97$ & 400 & $30-3000$ \\
WVTR $\times 10^{-12}\left(\mathrm{~kg} \mathrm{~m} \mathrm{~m}^{-2} \mathrm{~s}^{-1}\right)$ & 27.3 & 28.9 & $1.2-6.9$ & $4.5-5.9$ \\
$\mathrm{P}\left(\mathrm{O}_{2}\right) \times 10^{-18}\left(\mathrm{~kg} \mathrm{~m} \mathrm{~m}^{-2} \mathrm{~s}^{-1} \mathrm{~Pa}^{-1}\right)$ & $0.75-1.9$ & $2-2.9$ & 23.8 & $0.2-0.49$ \\
\hline
\end{tabular}

specific conditions of constant high temperature and humidity in industrial composting installations and are not fit for home composting nor do they compost in reasonable time when littered. PHAs are completely biodegradable in both soil and marine conditions in contrast to PLA polymers (Guillard et al. 2018).

The oxygen barrier properties are good, and twice as good as the oxygen barrier of PLA. The reasonable barrier properties along with the biodegradable nature of PHAs have facilitated the development of many commercial products based on this family of polymers (Bugnicourt et al. 2014). Yet, PHAs have limited applications in the packaging industry because of the current high production costs of these polymers.

In the 80s, Imperial Chemical industries developed poly (3-hydroxybutyrate-co-3-hydroxyvalerate) obtained via fermentation under the trade name of Biopol and was distributed in the US by Monsanto and later by Metabolix.

\section{Polybutylene succinate}

Polybutylene succinate (Gigli et al. 2016, Xu and Guo 2010) is a biodegradable aliphatic polyester with similar properties to those of PET. PBS is produced by condensation of 1,4-butandiol and succinic acid. Conventional processes for the production of 1,4-butandiol use fossil feedstocks. The bio-based process involves the use of glucose to produce succinic acid followed by chemical reduction to produce 1,4-butandiol.

PBS is a semi-crystalline polymer with a higher melting point than polylactic acid. In comparison with PLA, PBS is tougher but with lower rigidity and Young's modulus, but by changing the monomer composition mechanical properties can be tuned to suit applications. PBS decomposes naturally in water (Xu and Guo 2010) and has therefore poor water resistance and limited gas barrier properties, but better than PLA (Genovese et al. 2016). PBS can be processed into films, bags, or boxes for food packaging and has also other industrial applications, see, e. g., Babu et al. (2013).

The Japanese company Showa High Polymer started production of PBS 1993, and sold PBS under the trade name Bionolle, but terminated their production 2016. Other manufacturers include Mitsubishi Chemicals, and Chinese producers Hexing Chemicals and Xinfu Pharmaceutical and IRE Chemical in Korea (Babu et al. 2013).

\section{Poly(butylene adipate terephthalate)}

PBAT is synthesized (Zhao etal. 2010) from the polymer of 1,4-butanediol and adipic acid and the polymer of dimethyl terephthalate (DMT) with 1,4-butanediol. The polymer is a fully biodegradable polymer. The polymer has very limited water vapor resistance (Xie et al. 2016) and has a higher oxygen permeance than PLA. As with most biodegradable polymers, there are an extensive number of composite formulations that have been investigated with PBAT (Ferreira et al. 2019). Highlighted applications by manufacturers are cling wrap for food packaging, compostable plastic bags and water resistant coatings for various materials.

PBAT is produced commercially by many companies such as BASF under the name Ecoflex ${ }^{\circledR}$ and in a blend with poly(lactic acid) called Ecovio, by Novamont as Origo-Bi ${ }^{\circledR}$ and in a blend with starch called Mater-Bi ${ }^{\circledR}$, by Zhuhai Wango Chemical Co Ltd under the name Wango ${ }^{\circledR}$, by JinHui Zhaolong as Ecoworld ${ }^{\circledR}$ and in a blend with starch called Ecowill ${ }^{\circledR}$, and by Eastman Chemical as Eastar Bio ${ }^{\circledR}$ etc.

\section{Polysaccharides}

Polysaccharides are long-chain polymers formed from mono- or disaccharide repeating units joined together by 
glycosidic bonds. As a result of the large number of hydroxyl groups, there is extensive hydrogen bonding, which are important for film formation and for the characteristics of the films.

A variety of polysaccharides and their derivatives have been tested for potential use as edible packaging because they are abundant, low cost, and easy to handle.

Polysaccharides have good film forming properties and exhibit good mechanical and gas barrier properties and are efficient barriers against oil and lipids but offer little resistance to water migration.

Polysaccharides can easily be modified to improve their physiochemical properties by salt addition, solvent changes, heat gelatinization, $\mathrm{pH}$ changes, chemical modification of hydroxyl groups and cross-linking of polysaccharides, hydrolysis of polysaccharides, and employing various nanotechnology options (Nesic et al. 2019).

\section{Starch}

Starch is composed of two polymers, amylose and amylopectin. There are many reviews in this field such as Cazón etal. (2017), Jiménez etal. (2012), Thakur et al. (2019). Native starch molecules arrange themselves in the form of starch granules in which amylose and amylopectin are structured by hydrogen bonding in a semi-crystalline network.

The manufacturing of starch films is obtained by two techniques: the dry process and the wet process. The dry process is based on extrusion of thermoplastic starch (TPS). In this method the starch is plasticized and heated above its glass transition temperature in conditions of low water contents. In the wet process the starch is gelatinized, whereupon a film is formed and dried. The wet process is preferred to form edible preformed films, or to apply coatings by dipping, brushing or spraying. Nevertheless, the dry method is preferred for industrial applications.

Starch films have a good oxygen barrier at a low RH, but high water vapor permeability. It's common to use lipids in combination with starch and the most popular plasticizers are glycerol and sorbitol. The hydrophilic nature of starch and retrogradation phenomena limit their usefulness. Edible starch films and coatings are used in bakery, fresh fruits, confectionary and meat products.

\section{Cellulose, hemicelluloses and its derivatives}

Cellulose is composed of (1-4)- $\alpha$-D-glucopyranosyl units and is insoluble in water and paper materials do not con- stitute any significant barrier properties, with the exception micro/nanobased cellulosic materials, discussed separately below. On the other hand, there has been extensive research activities over many years in order to combine bioplastics with paper/paperboard materials, e.g., Andersson (2008), Aulin and Lindström (2011), Khwaldia et al. (2010), Rastogi and Samyn (2015), Su et al. (2018). Water soluble derivatives can be formed by etherification and the commonly commercial cellulose ethers are: methyl cellulose, carboxymethyl cellulose (Paunonen 2013), hydroxypropyl cellulose, hydroxypropyl methyl cellulose (Ghadermazi et al. 2019), which all have good film forming properties. Coatings of these derivatives have been applied to various foods to provide barriers to moisture, oxygen and oil resistance (Janjarasskul and Krochta 2010), but none of these derivatives have gas barrier properties at the high end of the scale.

There have also been extensive activities using hemicellulose barriers, e. g., review by Ibn Yaich et al. (2015).

\section{Chitosan}

Chitin is a $\beta-1,4-$ linked linear polymer of 2-acetamido-2deoxy-D-glucopyranosyl residues. It is made by treating the chitin shells of shrimp and other crustaceans with an alkaline substance, like $\mathrm{NaOH}$. The cationic amino groups of chitosan confers opportunities for chemical modification because cationic groups can react with negatively charged groups on polysaccharides such as carboxymethyl cellulose, alginate, pectins and various proteins, extracts like beeswax and synthetic polymers, and therefore there has been extensive investigations of chitin films recently, see reviews (Dufresne et al. 2013, Elsabee and Abdou 2013, Wang et al. 2018). Another advantage of chitosan is the antibacterial properties of this polymer. The cationicity has also been investigated with nanoclays, layer-by layer films as well as polyelectrolyte complexes for food packaging. A drawback is that chitosan is expensive, so new technologies are still needed for massproduction of chitosan-based films to meet packaging applications.

\section{Pectin}

Pectins are water-soluble anionic polymers composed mainly of $(1 \rightarrow 4)$ - $\alpha$-D-galactopyranosyluronic acid units. Pectins with a degree of esterification (DE) above $50 \%$ are labeled high-methoxyl pectin (HMP) and those below $50 \%$ are termed low-methoxyl pectin (LMP). The differences in 
methyl ester content and DE affect solubility and gelation properties of pectin. The main industrial sources for pectins are apple pomace and citrus peels. In general, edible films like pectin do not pretend to replace traditional food packaging materials, but is used for specific food related functions like antimicrobial functions, such as antibrowning, texture enhancers, probiotics, flavors etc. The manufacture of films is done by using the casting method or extrusion (Espitia et al. 2014, Janjarasskul and Krochta 2010).

\section{Alginate}

Alginate is a naturally occurring polysaccharide and is mainly derived from brown algae species. Alginate is a linear $(1 \rightarrow 4)$ linked polyuronic acid molecule containing three types of block structures. These highly anionic polymers have the ability to form strong gel structures by reacting with multivalent cations.

Monovalent salts of alginates are water soluble, but the solubility is limited at low pH-values. Alginate films can be formed from evaporating solvent from alginate gel or by a two-step procedure that involves drying of alginate solution followed by treatment with a calcium salt solution to induce cross-linking at the interface. Film strength and permeability can be altered by the concentration and type of polyvalent cations.

The rate of its addition and time of exposure, $\mathrm{pH}$, temperature, and the presence of composite constituents are important. Owing to their good $\mathrm{O}_{2}$ barrier properties, alginate coatings can protect foods against oxidation but has a high water vapor permeability (Janjarasskul and Krochta 2010, Kester and Fennema 1986, Senturk Parreidt et al. 2018).

\section{Carrageenan}

Carrageenan is a complex mixture of several polysaccharides. Three principal carrageenan fractions, kappa $(\kappa)$, iota ( () , and lambda $(\lambda)$, differ in sulfate ester and 3,6-anhydro- $\alpha$-D-galactopyranosyl content, which results in various degrees of negative charge and solubility in water. Thermo-reversible carrageenan gels can be used as food coatings to retard moisture loss from an enrobed food by acting as a sacrificing agent. Carrageenan has been applied to a variety of foods to carry antimicrobials and to reduce moisture loss, oxidation, or disintegration (Janjarasskul and Krochta 2010, Kester and Fennema 1986).

\section{Proteins}

Proteins are made up of many different amino acids linked together. Amino acids can be categorized into various groups on the type of interaction they create, such as covalent bonding, ionic, disulfide cross-linking or hydrogen bonding. There are twenty different types of these amino acid building blocks commonly found in plants and animals.

Only few of the many proteins are widely commercially available for packaging applications, and high costs and unfavorable technical properties make many proteins less interesting for packaging. The intrinsic hydrophilicity of proteins results in good adhesion to polar surfaces such as paper materials and they provide good gas barriers but have limited water vapor resistance. Cross-linking plays a fundamental role for proteins in order to enhance their water vapor barriers. Procedures such as thermal crosslinking, enzymes, such as transglutaminase can crosslink proteins and disulfide crosslinking, or chemical crosslinking using, e. g., glutaraldehyde, formaldehyde and glycol are also common methods. Plasticizers are usually required in the development of protein films in order to acquire the desired physiochemical properties such as material flexibility.

There are two major processes for making protein films: a wet process based on dispersion and solubilization of proteins and a dry process based on the thermoplastic properties of proteins, when they are extruded.

It will be obvious that the proteins have many similarities regarding their barrier properties. The oxygen permeability of proteins is very good at low RH-conditions because of their hydrophilicity, but it also results in a high water vapor permeability. Therefore, developments focus often on multilayering or use of nanocomposites, and the cost for that may be offset if the proteins are cheap byproducts from other manufacturing uses of proteins.

Most proteins have been subjected to various bionanocomposite materials and there are many recent reviews on these investigations, e. g., Coltelli et al. (2015), Zink et al. (2016), Zubair and Ullah (2020).

\section{Casein and caseinates}

Casein is the principal protein fraction in cow milk, which accounts for $80 \%$ of its total protein content and is used ubiquitously by the food industry. Casein appears as micelles with $50-300 \mathrm{~nm}$ micelles and is relatively heat sta- 
ble. In contrast to whey proteins, caseins lack sulfhydrylgroups, hence they do not show the typical denaturation behavior of proteins.

Caseins are precipitated from the milk by adjusting the $\mathrm{pH}$ to the isoelectric point. Casein tends to aggregate once dried but the functionality of the protein can be restored by re-neutralization using alkali. The Na-caseinate (NaCAS) can be dissolved in water and forms easy to films. Like most proteins NaCAS shows a high water vapor permeability, but shows a higher oxygen barrier than nonionic polysaccharides, and has high cohesive energy density and a low free volume (Miller and Krochta 1997). It has been reported that carnauba wax and glycerol had a strong effect on the water vapor barrier. Whereas glycerol had increased the permeability, the carnauba waxes strongly decreased the permeability. There have been many efforts to crosslink casein in various ways, but the effects of an enhanced water vapor barrier have not been confirmed. On the other hand, the water vapor permeability can be enhanced by molecular weight and developed crystallinity (Coltelli et al. 2015, Khwaldia et al. 2010, Zink et al. 2016).

\section{Whey proteins}

Whey protein is the soluble part of the milk and constitutes about $20 \%$ of the total amount of the proteins. As whey protein is a by-product of cheese and casein manufacturing, it's highly available but still underused due to its high water content and high processing and transportation costs.

In order to manufacture whey proteins, they are processed by membrane and ion exchange chromatography techniques, followed by spray drying to create purified whey protein isolate powders (WPI). WPI contains above $90 \%$ protein based on dry matter and comprise $\alpha$-lactalbumin and $\beta$-lactoglobulin in a ratio of 1:4 when manufactured using the membrane process and somewhat less $\alpha$-lactalbumin when employing the chromatography process. B-lactoglobulin contains disulphide bonds and a free thiol group, which can form disulphide bridges once the molecule is unfolded. Due to the crosslinking and intermolecular hydrogen bonds, whey proteins provide excellent oxygen barrier properties and at low RH, the oxygen permeability is in the range of EVOH polymers and is therefore useful to improve the oxygen barrier properties of food packaging. Whey proteins are also useful for oil resistance (Coltelli et al. 2015, Khwaldia et al. 2010, Zink et al. 2016).

\section{Gelatin}

Gelatin refers to a purified and modified collagen protein. Collagen is the primary component in animal connective tissue such as cartilages, skins and bones and appears in a fibrous triple helical structure consisting of three proteins.

There are two types (A and $\mathrm{B}$ ) that are synthesized by partial hydrolysis of collagen proteins. The type $A$ is extracted by acid hydrolysis, whereas the B-type is prepared by solubilization with alkali at a temperature between $60-90^{\circ} \mathrm{C}$. Gelatin is a heterogeneous mixture comprising glycine, 4-hydroxyproline and proline contents. Gelatin has suitable film forming properties with good adhesiveness and good barrier properties against oxygen and aroma but is brittle and plasticizers, e.g., polyvinyl alcohol (PVA) and sorbitol, are necessary for most applications. The best treatments for improving the water vapor barrier has been found to be enzymatic treatments, because of the fact that the polymer is partly hydrophobic. Cross-linking is not significant for the oxygen barrier properties (Coltelli et al. 2015, Khwaldia et al. 2010, Zink et al. 2016).

\section{Wheat gluten}

Wheat gluten is known to form elastic networks for a wide range of bakery and other food products since centuries. Gluten is a generic term for more than 50 different electrolyte insoluble wheat flour proteins of different classes representing up to $85 \%$ of all proteins. Gluten contains glutelin, prolamin fractions, referred as glutenin and gliadin, respectively. Although insoluble in most natural waters, wheat gluten can be dissolved in aqueous solutions at high or low pH-values (avoiding the isoelectric point of proteins) at low ionic strength.

The ability of glutenin to form covalent disulphide bonds and covalent bonds with tyrosine side chains account for the elastic properties of gluten networks.

The manufacture takes place by shearing wheat flour with water, which enables the separation and purification of aggregated wheat gluten in industrial scale, while separating the starch, fibres and other components in the water.

Gluten films are typically prepared from aqueous alcoholic protein solutions. The manufacturing of gluten films takes place by solvent coating, aided by mechanical mixing, heating as well as adjustments to acid and alkaline conditions. The breaking of native disulphide bonds takes place during heating, resulting in free thiol groups, which can form new bonds during drying. 
As with other hydrophilic proteins, gluten films have good oxygen barriers at low RH while the water vapor barriers are low. Films prepared from the glutenin fraction show higher water vapor permeability than those produced by the gliadin fraction (Coltelli et al. 2015, Khwaldia et al. 2010, Zink et al. 2016).

\section{Soy protein}

Proteins from soy consist of two principal components and about $20 \%$ stems from water soluble albumins, whereas the major fraction exists of large globular storage proteins. In soy, these proteins are named ß-conglycinin and glycinin. The aqueous extraction procedure to manufacture soy protein isolates (SPI) is based on alternating increases and decreases in the $\mathrm{pH}$, akin to other protein extraction procedures. The soy protein isolates are usually a by-product from the soybean oil industry. Soybean films show good-film-forming properties and is useful for edible films and coatings and are often produced by aqueous casting. The plasticizer mainly used is glycerol and by using plasticizers, dry processes like extrusion can also be possible. Like other protein films the oxygen permeability is reasonably good, but the water permeability is high, but it has been observed that thermally induced cross-linking of the barriers can decrease the water vapor permeability (Coltelli et al. 2015, Khwaldia et al. 2010, Zink et al. 2016).

\section{Corn Zein}

Corn contains all the Osborne fractions of proteins (albumins, globulins, prolamin and glutelin). The prolamin fraction is named corn zein or corn gluten and is the principal component in corn, where it represents about $50 \%$ of the protein followed by glutelin. The protein composition varies, however, widely depending on the corn variety. Zein consists of a polypeptide with a molecular weight of $85 \mathrm{kDa}$ or higher and zein dissolves in $70-80 \%$ aqueous ethanol or pure propanol and is insoluble in water at room temperature. The commercial manufacture of zein is based on products extracted with aqueous-alcoholic and contain a purity greater than $90 \%$. The manufacturing of zein protein isolates (ZPI) is more sophisticated than proteins from other plants and therefore zein isolates are quite expensive. The barrier properties suffer similar disadvantages as other proteins, so to produce efficient barriers, the developments of multilayering products are considered similar to the above proteins (Coltelli et al. 2015, Khwaldia et al. 2010, Zink et al. 2016).

\section{Lipids, waxes, and resins}

Many lipids, waxes and other resin materials have been utilized as protective coatings against moisture transfer. There are disadvantages of employing these materials in packaging materials, such as their waxy taste and texture, greasy surface, and potential rancidity. The lipid component in formulations reduce the water transmission and the hydrocolloid component serve as a gas barrier and provide some strength and structural integrity.

Waxes are esters with a long-chain fatty acid with a long-chain alcohol. Waxes are more resistant to diffusion of water than lipids owing to their low level of polar groups. Typical waxes are carnauba wax, candelilla wax, rice bran wax, beeswax and synthetic waxes such as paraffin wax and petroleum wax and have been used as protective coatings alone or as components with other ingredients. Edible resins such as shellac, terpene and wood resin have also been used in various formulation (Aulin and Ström 2013, Janjarasskul and Krochta 2010, Kester and Fennema 1986).

\section{Nanotechnologies and food packaging}

From the very beginning of the emergence of various nanotechnologies, such technologies were considered to have a high potential for food packaging. Nanotechnologies have, however, failed to have the large expected use, mainly because of uncertainties regarding safety issues, life-cycle consideration, recycling etc. which have limited legal and consumer acceptance. Regulatory and toxicity issues, migration issues, as well as environmental considerations and various nanotechnology applications for packaging have been given extensive reviews recently (Wyser et al. 2016, Din et al. 2020).

The range of nanomaterials and nanotechnologies are extremely broad and span into the fields of active and intelligent packaging in various forms such as oxygen scavengers, antimicrobial packaging, freshness indicators, interactive packaging etc, and are not considered in this context.

During the last decades, a number of different routes to develop new types of packaging materials, such as the use of nanocellulose, nanoclays, LbL technology and polyelectrolyte complexes. Apart from these technologies, a general trend in the literature is the focus on different blends of materials, see, e. g., Din et al. (2020). 
There is also the field of nano-inspired oxygen barrier coatings, which dates back to the end of the last century, when the Ormocer ${ }^{\circledR}$ coating technology was developed at the Fraunhofer institute (Haas et al. 1999). This was probably one of the first relevant examples for food packaging applications using nanocoatings (Rovera et al. 2020). It should be mentioned that there is a large field of advanced hybrid organic-inorganic nanomaterials with numerous different applications (Sanchez et al. 2011).

A selected number of general reviews are suggested to mirror these developments (Amass et al. 1998, Duncan 2011).

\section{Nanocellulose and food packaging}

The original inventors of microfibrillar cellulose (Herrick et al. 1983, Turbak et al. 1983), later called nanofibrillar cellulose or cellulose nanofibrils (CNF) in the late 90s were simply produced by delamination of fibres through high-pressure homogenizers, but later it was understood that chemical/enzymatic treatment and hydrolysis pretreatments of pulps could decrease the energy consumption during delamination to a large extent and could also produce materials with a higher content of the elementary fibrils.

There are three major families of nanocellulosic materials: CNF (width: 5-60 nm; length over a micrometer), cellulose nanocrystals (CNC) (width 5-70 nm; length 100$250 \mathrm{~nm}$ ) and bacterial nanocellulose (width $20-100 \mathrm{~nm}$; length exceeding micrometers) (Klemm et al. 2011) and there are numerous reviews on the manufacture and properties of CNF materials in the field, e.g., Klemm et al. (2011), Moon etal. (2011), Isogai et al. (2011), Siró and Plackett (2010) to which the reader is referred to regarding their manufacturing processes and properties. In the context of food packaging materials, the CNF materials are in focus. Apart from the mechanical properties of CNF films and composite materials, their oxygen and moisture permeability together with grease and oil resistance is in focus. It should be noted that CNF materials have been found to be a better gas barrier than CNC materials (Belbekhouche et al. 2011). There is an extensive number of publications and many excellent reviews on the use of CNF materials in the field of packaging, e. g., Abdul Khalil et al. (2016), Bharimalla et al. (2019), de Azeredo etal. (2017), Ferrer et al. (2017), Hubbe etal. (2017), Lavoine et al. (2012), Lavoine et al. (2014), Scaffaro et al. (2016). When it comes to the oxygen barrier properties, it was early recognized that highly charged films produced higher density films compared to non-treated fibres or enzymatically

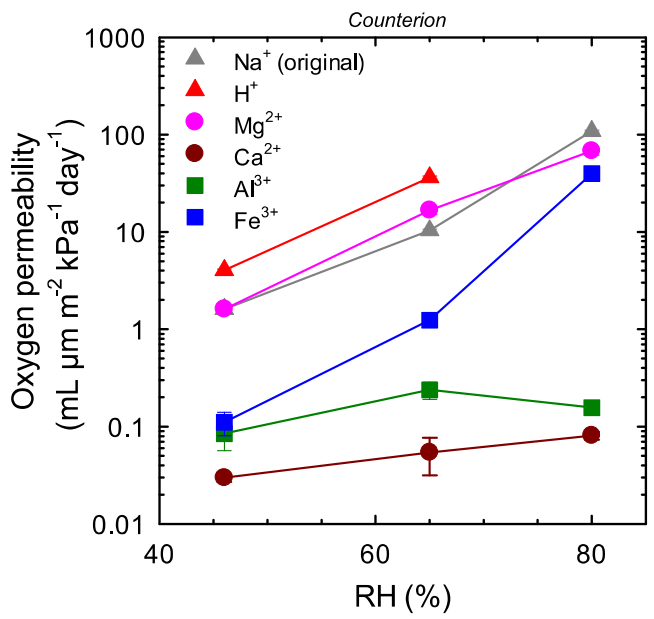

Figure 5: Oxygen permeability of the original TOCN-COONa and ionexchanged TOCN-COOM films under various conditions (Shimizu et al. 2016).

treated films (Aulin etal. 2010a, 2010b, Fujisawa et al. 2011, Minelli et al. 2010, Syverud and Stenius 2009). Basically, the higher the charge density, the higher is the film density and the oxygen permeability decreases the higher the carboxyl group content as illustrated in Table 3.

Another very important factor is the effects of the counterion. It has been found that if the sodium salt is exchanged to a cation of higher valency, e.g., $\mathrm{Ca}^{2+}$, the oxygen permeability decreases two orders of magnitude, as shown in Figure 5. As the authors (Minelli et al. 2010, Shimizu et al. 2016) discussed, there is no simple order in terms of metal ion valency and the oxygen permeability is considerably lower for the $\mathrm{Ca}^{2+}$ ion compared with the $\mathrm{Mg}^{2+}$ ion, which is not easy to understand, but is an interesting result. The upscaling is not straightforward as anion-exchange in water will induce flocculation, which may destroy the films if the ion-exchange isn't made by repressing the water through the film as the investigators did.

Because of a high crystallinity and a high cohesive energy density such films have a superior oxygen barrier compared to other polymers (Figure 6) but only at a low relative humidity. At a high relative humidity the oxygen barrier is destroyed and the permeability increases with several orders of magnitude (Figure 7). This is by no means surprising as the moisture content swells the films and open up the films for gas transfer. All biodegradable materials sorb moisture so a low oxygen barrier is akin to all biopolymers.

The films have a density close to the density of cellulose, indicating little porosity, but only at higher basis weights than $3-5 \mathrm{~g} / \mathrm{m}^{2}$. Obviously, there are more pores 
Table 3: Characteristics of sodium carboxylated CNF films on 50 micrometers PET-films at $0 \%$ RH. Adapted from Wang et al. (2017).

\begin{tabular}{rrrrr}
\hline Oxygen permeability $\left(\mathbf{c m}^{\mathbf{3}} \mathbf{~ m i c .} / \mathbf{m}^{\mathbf{2}}\right.$ day) & Coating (mic.) & Carboxylate (mmol/g) & Dp & Density $\left(\mathbf{g} / \mathbf{c m}^{\mathbf{3}}\right)$ \\
\hline 0.17 & 1 & 1.74 & 1440 & 1.47 \\
4 & 1,5 & 1.5 & 550 & 1.43 \\
4 & 1 & 1.4 & 400 & 1.45 \\
10 & 1 & 1.2 & 550 & 1.11 \\
107 & 2 & 0.8 & 690 & 1.10 \\
1293 & 5 & 0.3 & 920 & 1.13 \\
\hline
\end{tabular}

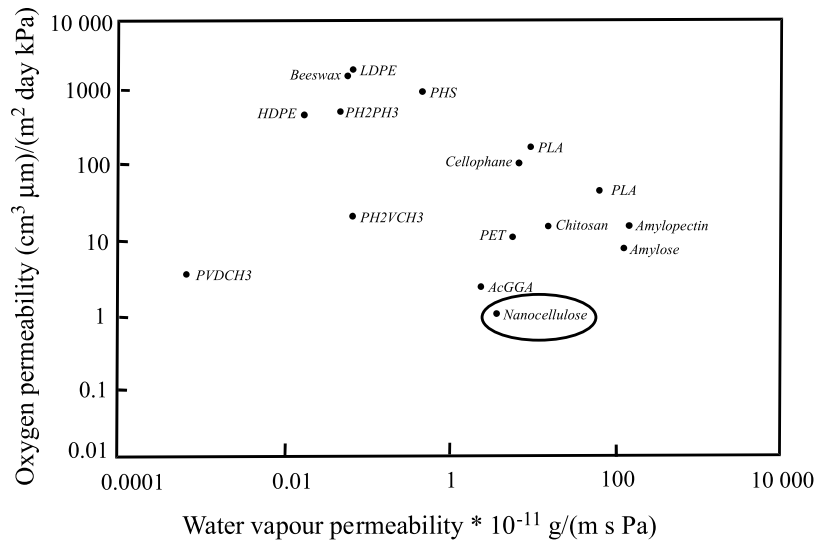

Figure 6: Oxygen permeability and water vapour permeability of some polymers at $50 \%$ RH (Aulin et al. 2010a).

at the surface of the films, which was also concluded by Minelli and co-workers (Minelli et al. 2010).

When it comes to the moisture barrier properties of CNF-films they are inherently inferior because of the moisture uptake. The use of waxes, such as paraffin, candelilla, carnauba, beeswax to decrease the moisture and water barrier properties of paper has been known to papermakers for more than 100 years, see, e. g., Minelli et al. (2010), Donhowe and Fennema (1993) but has also been investigated for nanocellulose, e.g., Spence et al. (2011) and alkyd resins (Aulin and Ström 2013, Dufresne 2018) and beeswax (Hult et al. 2010).

At this point it should also be remembered that nanocellulosic materials have been extensively investigated as green nano reinforcements for polymer nanocomposites (Dufresne 2018).

\section{Nanoclays in food packaging}

The first steps toward the fabrication of polymer-clay hybrid materials goes back the developments Toyota Central Research and Development Laboratory in the mid 80 s. The technology was demonstrated with a nanome-

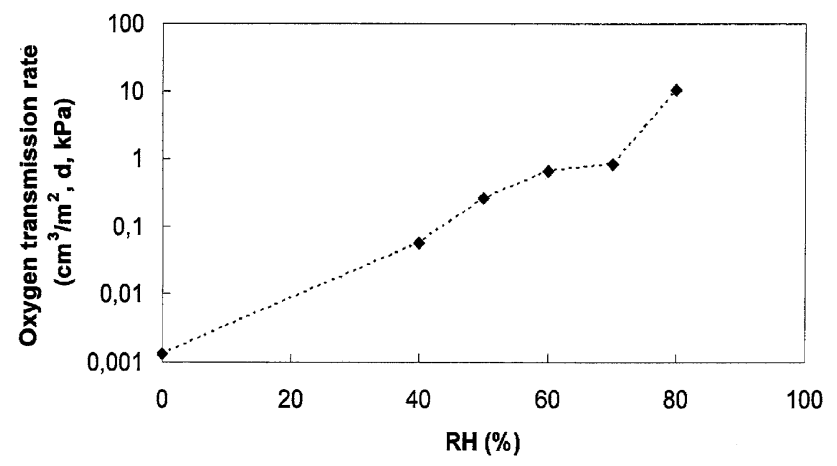

Figure 7: Oxygen barrier properties for a carboxymethylated CNF at different relative humidities (Aulin et al. 2010a).

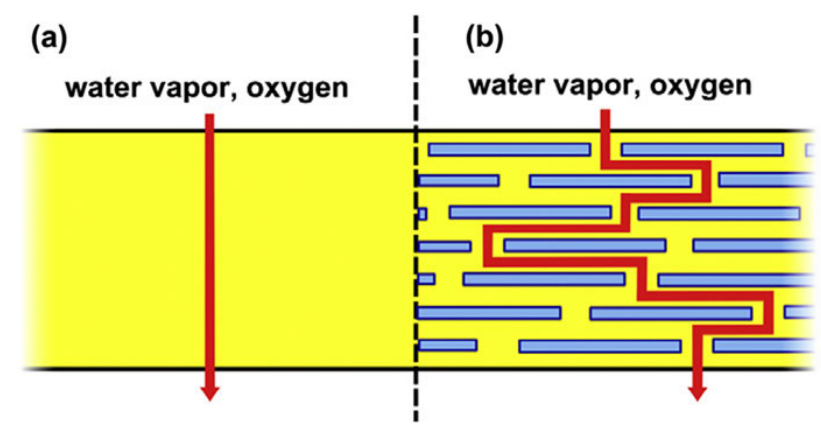

Figure 8: Illustration of the tortuous pathway created by incorporation of exfoliated nanoclay in a polymer matrix film (Duncan 2011).

ter sized composite of nylon- 6 and a nanometer thick exfoliated aluminosilicate (Kojima et al. 1993). This constituted a new type of composite material that could exhibit large improvements in mechanical, barrier properties and high transparency by means of nanofiller geometry and a high surface area exceeding higher than $500 \mathrm{~m}^{2} / \mathrm{g}$. The increased diffusion distance for a penetrant through a film is caused by the increased tortuosity, which decreases the gas penetration, see the cartoon in Figure 8 . The primary mechanism is the tortuosity pathway, but there is also changes in the polymer-particle interaction at the interface region. If there is a strong interaction between the 


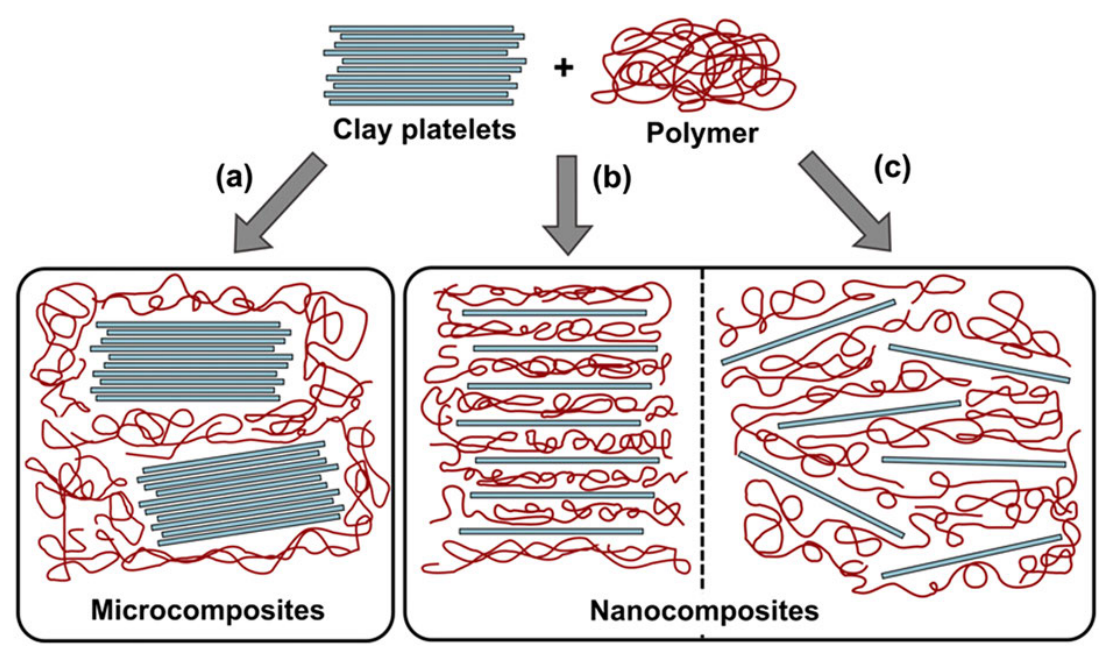

Figure 9: Three types of composites when layered clays are incorporated with a polymer: a) tactoid, phase separated microcomposite; b) intercalated nanocomposte; c) exfoliated polymer-clay nanocomposite (Duncan 2011).

nanoparticle and the polymer, the polymer interface can be immobilized, which causes a decreased hopping rate between free volumes a fact that has been observed via positron annihilation lifetime spectroscopy (PALS), see, e. g., Choudalakis and Gotsis (2009).

The nanoclays could have a thickness in the order of a few $\mathrm{nm}$ and flakes with a width up to $100 \mathrm{~nm}$. The nanoclays investigated for this purpose are mostly from the group of 2:1 phyllosilicates, including minerals such as montmorillonite, hectorite, saponite, vermiculite. Montmorillonites $\left.\left(\mathrm{Si}_{8}\right)\left(\mathrm{Al}_{4-y} \mathrm{Mg}_{y}\right) \mathrm{O}_{20}(\mathrm{OH})_{4}\right)$ are by far the most investigated minerals among the phyllosilicates. A wide range of nano-biocomposites have been investigated such as. PCL, PLA, PHA, starches, chitosan etc. (Alexandre and Dubois 2000, Giannelis et al. 1999, Rhim et al. 2013, Rhim and Ng 2007, Sinha Ray and Okamoto 2003, Sinha Ray et al. 2002).

The phyllosilicates mainly present three different multi-scale structures as shown in Figure 9:

a. Aggregated particles (tactoids), where the size of the particles is from 0.1 micron to 10 microns (microcomposite structures).

b. Aggregated particles with a thickness of $10 \mathrm{~nm}$. Intercalated structures are obtained by a moderate expansion of the clay interlayer.

c. Disc or a platelet having a width from $10 \mathrm{~nm}$ up to 1 micrometer and a thickness of $1 \mathrm{~nm}$. (Exfoliated structure). The clay should be exfoliated into a singlet platelet and distributed homogeneously throughout the polymer matrix to take full advantage of the high surface area of the clays.
The incorporation of the nanoclay, may be carried out with three major procedures:

a. In situ polymerization. In this method layered silicates are swollen into a monomer solution, but this can obviously not be the case for polysaccharides, as they are synthesized during growth.

b. Solvent intercalation. This process is based on a solvent system that can swell the silicate layers (aqueous systems) and this is the natural way for polysaccharides, which can be melt processed due to thermal degradation.

c. Melt intercalation process.

The clays have in general a negative charge resulting from the fact that the silica $\left(\mathrm{Si}^{4+}\right)$ is substituted by aluminium cations $\left(\mathrm{Al}^{3+}\right)$ in the clay structure. The negative charges are very important for the dispersion of the flakes into the polymeric matrix and it's important to be able to modify their surface characteristics through ion-exchange reactions.

Generally, many matrix materials are hydrophobic and it is important to reduce the interfacial energy or reducing the cohesive force between the clay and the matrix. For hydrophobic matrix materials the most used method is to use ammonium cations attached to long chain alkyl chains $\left(\mathrm{C}_{14}-\mathrm{C}_{18}\right)$.

The use of nanohybrid composites for food packaging started some 15 tears ago, e. g., Chivrac et al. (2009), Duncan (2011), Ray et al. (2002), Sorrentino et al. (2007), Yang et al. (2007) and there are also several recent reviews in the field (Attaran et al. 2017, Kuswandi 2017, Youssef and ElSayed 2018). 

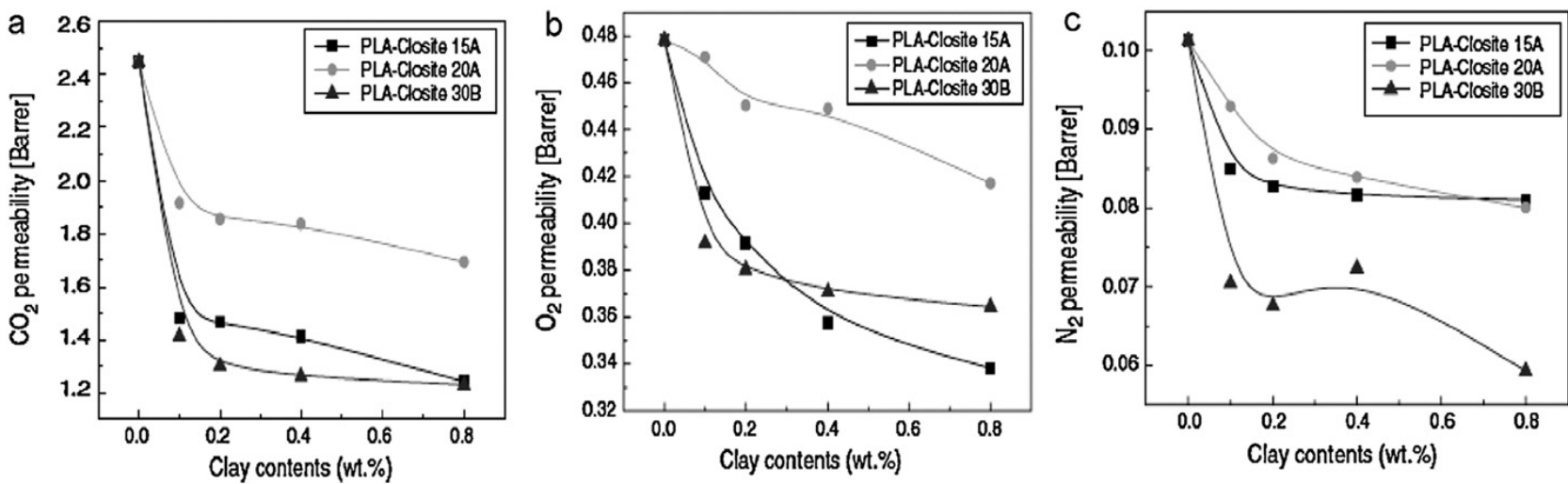

Figure 10: The effects of various types of montmorillonites on the carbon dioxide, oxygen and nitrogen permeability of PLA-clay composites (Rhim et al. 2013).

The tortuous diffusion of gas has also been modelled by Nielsen (1967) assuming the that the platelets are evenly dispersed throughout the matrix and supposes the tortuosity is the only factor influencing the gas diffusion. In this model the gas permeability is given by the following equation:

$$
K_{\text {composite }} / K_{\text {matrix }}=(1-\varnothing) /(1+0.5 \alpha \varnothing)
$$

where the K-values represent the permeabilities of the composite structure and of the matrix in absence of the platelets and $\varnothing$, the volume fraction of the platelets and $\alpha$, the aspect ratio of the of the platelets. Assuming a $10 \%$ volume fraction and an aspect ratio of 100 , the gas diffusion rate should decrease $12.5 \%$ of the gas diffusion in the polymer matrix. The Nielsen formula has also been verified by Choudalakis and Gotsis (2009).

An investigation of the gas permeation through nanohybrid materials (Attaran etal. 2017, Choudalakis and Gotsis 2009, Rhim et al. 2013) also reveal that the gas permeation (oxygen and moisture permeation) decreases less than an order of magnitude, which is helpful but requires additional measures to combat an inferior gas permeation. Figure 10 displays, for instance, typical data on the effects of different montmorillonite on the oxygen permeability of PLA-clay composites.

Biodegradability of bio-nanocomposites is one of the most interesting, but also controversial issues. Since the purpose for using biopolymers in nanocomposites materials is to utilize the biodegradability, it is important to secure that these composites are biodegradable. Most investigations have been made on PLA-nanocomposites and indeed it has been found that the biodegradability is enhanced in the nanocomposite when compared with the PLA polymer, see, e. g., reviews (Duncan 2015, Kumar et al. 2009, Rhim et al. 2013). The enhanced biodegradability may be explained by the high hydrophilicity of the clay, allowing an easier permeability of water into the polymer matrix and activating the degradation process.

Most investigations on nanocomposites have been executed on thermoplastic fossil-based polymers and there are only a smaller number of investigations on bio-nanocomposites, but still a considerable number of reviews, e.g., de Azeredo (2009), Ghanbarzadeh etal. (2015), Rhim etal. (2013), Reddy etal. (2013), Tang et al. (2012).

There is another related area to montmorillonite, namely Layered Double Hydroxides (LDH's), which is a class of lamellar anionic clays. The first was termed hydrotalcite, it was found in a Norwegian geological specimen. The LDH's aspire to replace aluminium packaging to enter the area of high barrier food packaging (Yu et al. 2019). The synthesis of LDH nanosheets is, however, extremely demanding because the very high in-plane charge density need to be over-comed requiring demanding exfoliation procedures, but has created orders of decreased oxygen and water vapor transmission rates.

\section{Layer-by Layer assembly to improve barrier properties}

Lbl-assembly is a technology to build multifunctional thin films through alternating exposure of a substrate to aqueous cationic and anionic polymers, see Figure 11. Instead of utilizing charged polymers the assembly can be built using nanoclays like montmorillonites, vermiculites etc. and various nanocellulosic substrates. The thickness of such films depends on the number of layers and the adsorption thickness. The adsorption thickness is depending on a number of many variables such as $M_{w}$ of poly- 


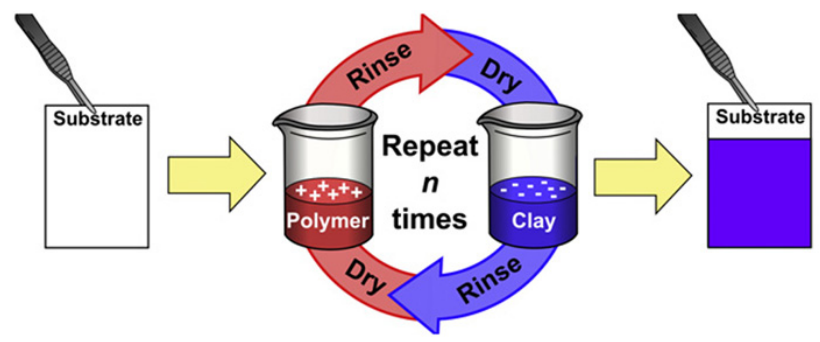

Figure 11: Outline of LbL assembly through electrostatic interaction (Duncan 2011).

mers used, $\mathrm{pH}$, ionic strength and type of counterion, deposition mixture and the relative humidity of the manufacturing environment. Typically, the films are fabricated to a thickness of 1-100 nm. This technology can be used to build Lbl layers by using various polyelectrolytes, but also using nanoclays and various nanocellulosic materials. After the report by Iler (1966) the group of Decher (Decher 1997, Decher and Schlenoff 2003) first realized and established the Lbl assembly and a recent review is also available (Richardson et al. 2015) reviewing the various Lblcategories: i) immersive, ii) spin, iii) spray, iv) electromagnetic, and v) fluidic assembly.

This method is a very elegant way to build multilayers though the method has its disadvantages with the upscaling (multiple deposition technology) of the technology and is not applicable for many kinds of nonamphiphilic materials (Ariga et al. 2007). By alternatively depositing oppositely charged materials conformal and ultra-thin coatings can be prepared by the Lbl- technology from aqueous environments (Li et al. 2020, Richardson et al. 2015). Lbl assembly is a nanocoating technology for gas barrier and gas separation coating (Qin et al. 2019a, 2019b, Song et al. 2018).

Interestingly, Lbl manufactured from PEI and CMC or CNF outperforms CNF-films with respect to oxygen permeability (Aulin et al. 2013). It was early found that Lbl manufactured from PEI and montmorillonite clay had such a low oxygen transmission $0.013 \mathrm{cc}\left(\mathrm{m}^{2}\right.$ day atm) that it was below the detection limit of commercial instruments (Priolo et al. 2010) (see Figure 12).

Despite excellent oxygen barriers polyelectrolyte multilayers (PEM) (Song et al. 2018) coatings have very limited moisture barrier coatings, loosened chain packing and higher chain mobility (Qin et al. 2019a). There are, however, approaches that may alleviate this problem. Hence, it has been shown that $\mathrm{SiO}_{x}$ sandwich between two PEM layers based on PEI and polyacrylic acid had a very high moisture resistance (Qin et al. 2019b).

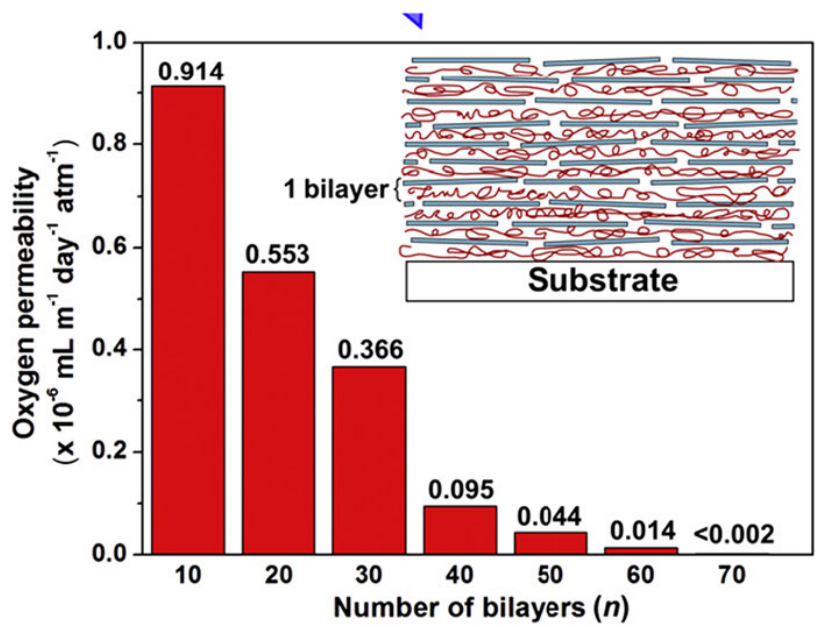

Figure 12: Oxygen permeability values for "brick wall” films of various bilayer numbers formed from branched poly(ethylene imine) (PEI) and sodium montmorillonite at pH 10 (Priolo et al. 2010).

\section{Multilayer micro and nanolayer co-extrusion}

Whereas, there has been extensive work on Lbl using dip coating, spraying and spin-coating, the upscaling of these technologies is often not suitable for large scale applications with the solvent manipulation. Multilayer (micronanolayer) coextrusion is such a technology (Li et al. 2020, Zhang et al. 2019), were layered composites can be manufactured with up to thousands of layers. This technology is not new but was developed by the Dow Chemical company in the 70s (Ponting et al. 2010). The uniqueness of this coextrusion technology is the combination of conventional coextrusion of two or more polymers in a layered feedblock with additional layer multiplication accomplished through a series of multiplayer dies. This design creates a highly flexible and novel process for production of polymer film with tens to thousands of layers, see Figure 13.

There are very few investigations dealing with this high barrier technology using biodegradable polymers, but this melt processing technology has been demonstrated at MIT using polyvinyl alcohol and polyhydroxyalkanoates (Thellen 2010).

\section{Polyelectrolyte complexes (PEC)}

The discussed Lbl technology has many advantages, but from a technological point, the many processing steps to make Lbl-films is an inherent disadvantage. It has, however, been shown that the sedimentation of PEC has been shown to produce coalesced and uniform thin films (Ball et al. 2013, Cain et al. 2014). Thin PEC-films have also been 
a

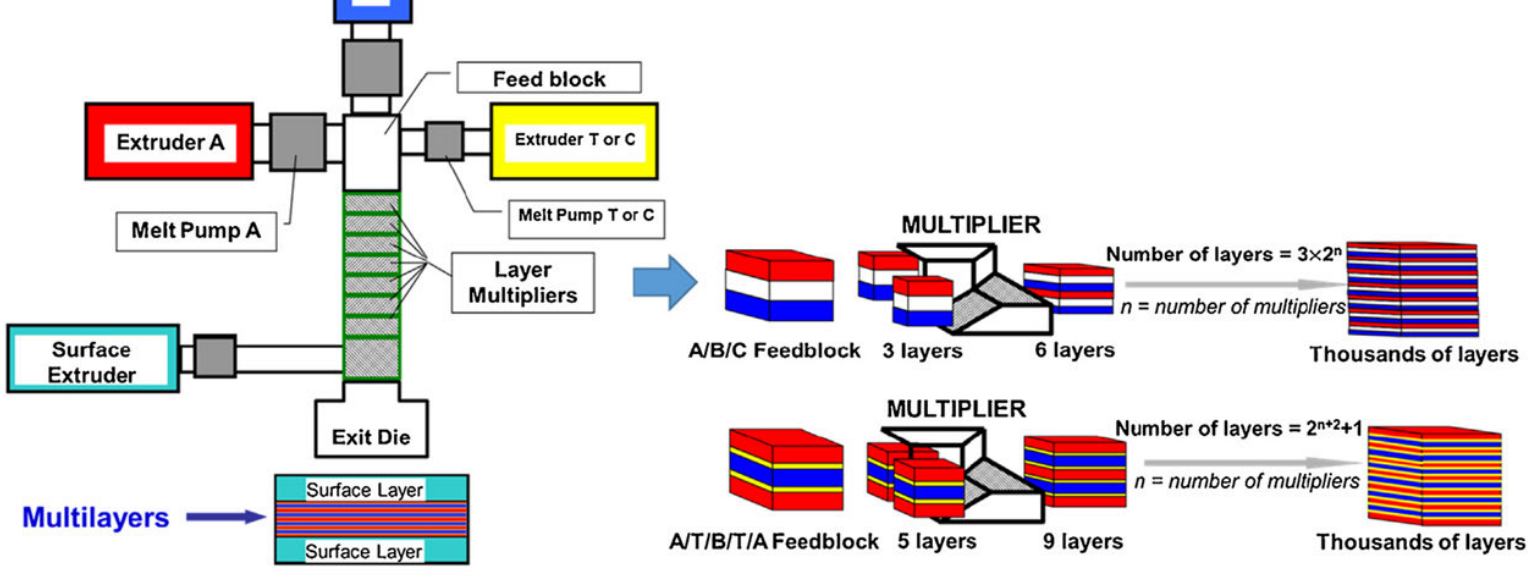

b

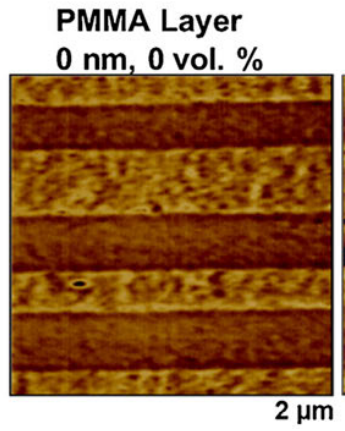

$25 \mathrm{~nm}, 8$ vol. $\%$

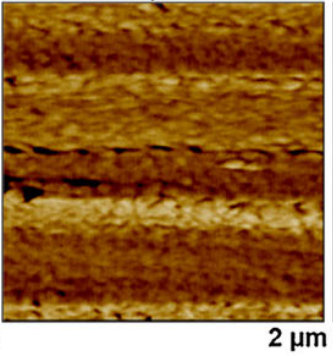

$63 \mathrm{~nm}, 20$ vol. $\%$

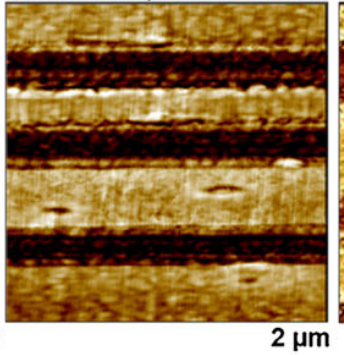

$103 \mathrm{~nm}, 33$ vol. $\%$

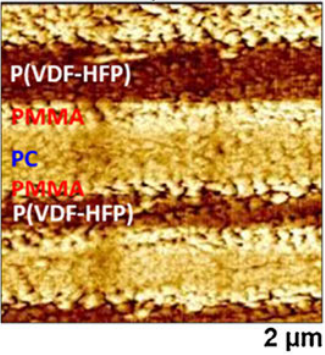

Figure 13: (Left) Two component multilayer system comprised of extruders, pumps, feedblock, multiplying dies, surface layer extruders, and exit die. (Right) Below: Layering structure of the composites (Li et al. 2020).

manufactured by spraying oppositely charged polyelectrolytes onto a substrate but in fewer steps similar to Lblfilms (Lefort et al. 2010, Porcel et al. 2005).

The formation of polyelectrolyte complexes is driven by the entropy gain, when the counterions are released from the polyelectrolytes and an interesting array of interesting morphologies are formed and there is an extensive number of publications to make PEC-films from oppositely charged biopolymers for food-packaging applications, see, e. g., Chi and Catchmark (2018a, 2018b), Farris et al. (2009), Ibn Yaich et al. (2015). These blends have been shown to have desirable gas-barrier properties when deposited onto substrates and has opened up opportunities for engineers to make novel food packaging systems. Nonetheless, the gas and water barrier properties of biopolymers are impaired at high relative humidities, which limits their applications in food packaging applications.

It should, however, be pointed out that the very thin films of PEC materials using non-biobased materials may not be a problem with regard to microplastic if nonbiobased PEC-films are deposited onto biobased plastics. Such systems constitute a viable route to efficient food packaging material also at high relative humidities. It has, for instance, been shown that a PEC-system of poly (diallyldimethylammonium chloride) and poly(acrylic acid), albeit not on a biobased substrate, but on a poly (ethylene terephtalate) film, decreased the oxygen transmission two orders of magnitude (Smith et al. 2018).

It should be pointed out that there are numerous parameters that must be controlled making PEC-systems: Apart from the choice of polymers the $M_{w}$ of the polymers, mixing order, the extent of homogenization and the polyelectrolyte concentrations, $\mathrm{pH}$, electrolyte conc. and zetapotential affect the various morphologies of the complexes (Sæther et al. 2008). It's very difficult to control the morphology at the iso-electric point of the complex because of coagulation and some charge overcompensation is necessary for control of the morphology as discussed by Fares and Schlenoff (2017). 
Finally, there is an emerging area of PEC with nanocellulosic materials that are promising, see, e.g., Chi and Catchmark (2018a).

\section{Safety issues, and toxicity of nanomaterials in food packaging}

Whereas, nanoclays like montmorillonites are considered as generally recognized as safe (GRAS) organomodified clays may not be safe. In food packaging, using hydrophobic barrier materials, the nanoclays are organically modified to allow for better exfoliation within the polymer matrix. The organic modification generally occurs through an ion-exchange reaction with a positively charged ion present between the nanoclay platelets. Examples of organomodified nanoclays used in food packaging are modifications like aminopropyltriethoxysilane and octadecylamine (Nanomer I.31PS), which have raised some concern, because they show some toxicity (Wagner et al. 2017).

This concern relates to the release of such nanoclays during manufacturing and disposal of food packaging materials, which may pose health concerns if the exposure is via inhalation and or ingestion routes.

The conclusion, however, is that the probability of migration into foods is very low as long as the nanoclays are completely embedded in the polymer matrix. However, due to mechanical impact, nanoparticles may come in contact with the food. Therefore, it is important to investigate migration of nanoparticles before and after flexing of food packaging materials (Bandyopadhyay and Ray 2019).

For nanocellulose there have been an overwhelming number of cytotoxic studies on nanocellulosic materials, basically concluding that there are no cytotoxic effects as defined by ISO Standard 109993-5, i.e. it does not reduce the cell viability by more than $30 \%$, see, e. g., CamareroEspinosa et al. (2016), Shatkin and Kim (2015).

There is, however, a concern over occupational inhalation exposure with handling of nanocellulose nanomaterials as dry powder and this has been the highest priority.

Basically, particles in the size of $5-50 \mathrm{~nm}$ can be stuck in the Alveolar part of the respiratory tract. Such particles are dangerous for the human health, because there are no enzymes breaking down cellulose in the lung tract and their bioduration will cause concern. Even though wood cellulose pulp, powdered cellulose, and microcrystalline cellulose are considered as safe materials, wood and cotton dust may contain cellulose nanoparticles among other constituents of wood and such dust has been shown to be cancerogenic and a well-known example is cotton dust in cotton factories. The current state of the risk analysis of nanocellulose materials by inhalation is that the quality of the available studies is generally inadequate for risk assessment (Ede et al. 2019). There are, however, numerous different nanocellulose materials, treated in different ways, having widely different morphologies and size distribution, and moreover they are difficult to characterize, which was a reason that a number of scientists recently published an extensive review and characterization issues (Foster et al. 2018, Shatkin 2020)

In conclusion, it's the occupational air dust exposure for both nanoclays and nanocellulose, which are of concern and appropriate engineering approaches must therefore be taken into account to assure the safety measures (Shatkin 2020).

\section{Outlook}

It is clear that nonbiodegradable plastics poses a major problem to the environment. Hydrophobic microplastics in the marine environment serve as a vector for the assimilation of persistent organic pollutants in the oceans and are transported into the food chain via marine life and animals in general. This constitutes a challenging threat to wild-life and also to the safety of foods in general. On the other hand, fossil-based plastics have a tremendous role for the preservation of foods and their security aspects and it's obvious that a single solution to secure food safety and these large environmental problems are not at hand. Historically, the use of biodegradable polymers has been considered as a solution to these environmental problems, but the evolution of biodegradable plastics has been retarded not only by economics due but to their inferior barrier properties, but also because that all biodegradable polymers must be susceptible to water sorption, which spoils the barrier properties at high humidities.

The European Commission has recently published a Green deal with strategies for a circular economy and for an industrial strategy. Requirements are published for an increased recycling and an inmixing of recycled plastics in new products as well as replacement of fossil based plastics. Microplastics are of special concern with restrictions of unintentional usage as well as promotion of biobased plastics.

The survey addresses food packaging demands and requirements for a safe food contact. Oxygen and humid barriers are essential properties of food packaging, which 
need to be addressed for alternative bioplastics. The survey describes some different materials to replace the traditional food safety plastics. A problem is the non-existence of a single replacement material, which will fulfill these requirements. There is a need for a combination of several materials in sandwich constructions and layer-bylayer techniques are identified options to achieve both oxygen and humidity barriers suitable for food packaging.

The evolution of biodegradable plastics points in several different directions: Firstly, the biodegradable polymers have not been enjoying large upscaling and its associated economic advantages. Secondly the use of blends between different biodegradable polymers to cope with economics (e.g., use of starch blends) and optimizing barrier performance and other properties and finally the emerging field of various nanotechnological solutions discussed in this review. Nanotechnology is of great interest with promising barrier properties. There is, however, the uncertainty regarding safety, toxicity and life-cycle considerations of nanomaterials, public skepticism and a legal acceptance needs to be taken into account.

It is obvious that there is not one solution like composting or incineration and other measures that will be the key to the alleviation of the environmental hazards, but a broad palette of technical and political solutions (legislative) that must be managed and will constitute a major challenge for mankind.

Acknowledgments: The authors acknowledge prof. Gunnar Henriksson, KTH for the rewriting of Figure 6.

Funding: Authors state no funding involved.

Conflict of interest: The authors declare no conflicts of interest.

\section{Abbreviations}

$\begin{array}{ll}\text { CNC } & \text { cellulose nano crystals } \\ \text { CNF } & \text { cellulose nanofibrils } \\ \text { DE } & \text { degree of esterification } \\ \text { DMT } & \text { dimethyl terephthalate } \\ \text { EOL } & \text { end-of-life } \\ \text { EPS } & \text { Expanded polystyrene } \\ \text { EVOH } & \text { ethylene vinyl alcohol } \\ \text { GRAS } & \text { generally recognized as safe } \\ \text { HMP } & \text { high-methoxyl pectin } \\ \text { LBL } & \text { layer-by layer } \\ \text { LDH } & \text { Layered Double Hydroxides }\end{array}$

LDPE low-density polyethene

LMP low-methoxyl pectin

MAP modified atmospheric packaging

$M_{w} \quad$ molecular weight

MT metric tons

NIR near infrared

OTR oxygen transmission rate

$\mathrm{PAH}$ polycyclic aromatic hydrocarbon

PALS positron annihilations lifetime spectroscopy

PBS polybutylene succinate

PBAT poly(butylene adipate-co-terephthalate)

PCB polychlorinated biphenyl

PCL polycaprolacton

PE polyethylene

PEC Polyelectrolyte complexes

PEM Polyelectrolyte multilayers

PET poly (ethylene terephthalate)

PHA polyhydroxyalkanoate

PHB poly(hydroxybutanolate)

PLA polylactic acid

PLGA poly(lactic-co-glycolic acid)

PP polypropylene

PPWD Packaging and Packaging Waste Directive

PVA polyvinyl alcohol

PVC polyvinyl chloride

SPI soy protein isolates

SUP single use plastic

TPS thermoplastic starch

UV ultraviolet

VIS visible spectroscopy

WPI whey protein isolate powders

WVT water vapor transmittance

ZPI zein protein isolates

\section{References}

Abdul Khalil, H.P.S., Davoudpour, Y., Saurabh, C.K., Hossain, M.S., Adnan, A.S., Dungani, R., Paridah, M.T., Islam Sarker, M.Z., Fazita, M.R.N., Syakir, M.I., Haafiz, M.K.M. (2016) A review on nanocellulosic fibres as new material for sustainable packaging: Process and applications. Renew. Sustain. Energy Rev. 64:823-836.

Alexandre, M., Dubois, P. (2000) Polymer-layered silicate nanocomposites: preparation, properties and uses of a new class of materials. Mater. Sci. Eng., R Rep. 28(1-2):1-63.

Amass, W., Amass, A., Tighe, B. (1998) A review of biodegradable polymers: Uses, current developments in the synthesis and characterization of biodegradable polyesters, blends of biodegradable polymers and recent advances in biodegradation studies. Polym. Int. 47:89-144. 
Andersson, C. (2008) New ways to enhance the functionality of paperboard by surface treatment - a review. Packag. Technol. Sci. 21(6):339-373.

Anjum, A., Zuber, M., Zia, K.M., Noreen, A., Anjum, M.N., Tabasum, S. (2016) Microbial production of polyhydroxyalkanoates (PHAs) and its copolymers: A review of recent advancements. Int. J. Biol. Macromol. 89:161-174.

Ariga, K., Hill, J.P., Ji, Q. (2007) Layer-by-layer assembly as a versatile bottom-up nanofabrication technique for exploratory research and realistic application. Phys. Chem. Chem. Phys. 9(19):2319-2340.

Armentano, I., Bitinis, N., Fortunati, E., Mattioli, S., Rescignano, N., Verdejo, R., Lopez-Manchado, M.A., Kenny, J.M. (2013) Multifunctional nanostructured PLA materials for packaging and tissue engineering. Prog. Polym. Sci. 38(10-11):1720-1747.

Attaran, S.A., Hassan, A., Wahit, M.U. (2017) Materials for food packaging applications based on bio-based polymer nanocomposites. J. Thermoplast. Compos. Mater. 30(2):143-173.

Aulin, C., Gällstedt, M., Lindström, T. (2010a) Oxygen and oil barrier properties of microfibrillated cellulose films and coatings. Cellulose 17:559-574.

Aulin, C., Karabulut, E., Tran, A., Wågberg, L., Lindström, T. (2013) Transparent nanocellulosic multilayer thin films on polylactic acid with tunable gas barrier properties. ACS Appl. Mater. Interfaces 5(15):7352-7359.

Aulin, C., Lindström, T. (2011) Biopolymer coatings for paper and paperboard. In: Biopolymers - New Materials for Sustainable Films and Coatings. Eds. Plackett, D.. John Wiley \& Sons Ltd, Chichester, West Sussex, UK.

Aulin, C., Netraval, J., Wågberg, L., Lindström, T. (2010b) Aerogels from nanofibrillated cellulose with tunable oleophobicity. Soft Matter 6:3298-3305.

Aulin, C., Ström, G. (2013) Multilayered alkyd resin/nanocellulose coatings for use in renewable packaging solutions with a high level of moisture resistance. Ind. Eng. Chem. Res. 52(7):2582-2589.

Auras, R.A., Lim, L.-T., Selke, S.E., Tsuji, H. Poly (Lactic Acid): Synthesis, Structures, Properties, Processing and Applications. John Wiley \& Sons, 2011.

Auta, H.S., Emenike, C.U., Fauziah, S.H. (2017) Distribution and importance of microplastics in the marine environment: $A$ review of the sources, fate, effects, and potential solutions. Environ. Int. 102:165-176.

Babu, R.P., O'Connor, K., Seeram, R. (2013) Current progress on bio-based polymers and their future trends. Prog. Biomater. 2:8-14.

Bagheri, A.R., Laforsch, C., Greiner, A., Agarwal, S. (2017) Fate of so-called biodegradable polymers in seawater and freshwater. Glob. Chall.. 1(4):1700048.

Ball, V., Michel, M., Toniazzo, V., Ruch, D. (2013) The possibility of obtaining films by single sedimentation of polyelectrolyte complexes. Ind. Eng. Chem. Res. 52(16):5691-5699.

Bandyopadhyay, J., Ray, S.S. (2019) Are nanoclay-containing polymer composites safe for food packaging applications? An overview. J. Appl. Polym. Sci. 136:12.

Belbekhouche, S., Bras, J., Siqueira, G., Chappey, C., Lebrun, L., Khelifi, B., Marais, S., Dufresne, A. (2011) Water sorption behavior and gas barrier properties of cellulose whiskers and microfibrillar films. Carbohydr. Polym.. 83(4):1740-1748.
Bharimalla, A.K., Patil, P.G., Mukherjee, S., Yadav, V., Prasad, V. (2019) Nanocellulose-polymer composites: novel materials for food packaging applications. In: Polymers for Agri-Food Applications. Eds. Guitiérrez, T. J. Springer Nature Switzerland AG.

Bordes, P., Pollet, E., Averous, L. (2009) Nano-biocomposites: Biodegradable polyester/nanoclay systems. Prog. Polym. Sci. 34(2):125-155.

Bugnicourt, E., Cinelli, P., Lazzeri, A., Alvarez, V.A. (2014) Polyhydroxyalkanoate (PHA): Review of synthesis, characteristics, processing and potential applications in packaging. eXPRESS Polym. Lett. 8:791-808.

Bumbudsanpharoke, N., Ko, S. (2015) Nano-food packaging: an overview of market, migration research, and safety regulations. J. Food Sci. 80(5):R910-R923.

Cain, A.A., Murray, S., Holder, K.M., Nolen, C.R., Grunlan, J.C. (2014) Intumescent nanocoating extinguishes flame on fabric using aqueous polyelectrolyte complex deposited in single step. Macromol. Mater. Eng. 299(10):1180-1187.

Camarero-Espinosa, S., Endes, C., Mueller, S., Petri-Fink, A., Rothen-Rutishauser, B., Weder, C., Clift, M., Foster, E. (2016) Elucidating the potential biological impact of cellulose nanocrystals. Fibers 4(4):21.

Castro-Aguirre, E., Iniguez-Franco, F., Samsudin, H., Fang, X., Auras, R. (2016) Poly(lactic acid)-Mass production, processing, industrial applications, and end of life. Adv. Drug Deliv. Rev. 107:333-366.

Cazón, P., Velazquez, G., Ramírez, J.A., Vázquez, M. (2017) Polysaccharide-based films and coatings for food packaging: A review. Food Hydrocoll. 68:136-148.

Chi, K., Catchmark, J.M. (2018a) Improved eco-friendly barrier materials based on crystalline nanocellulose/chitosan/ carboxymethyl cellulose polyelectrolyte complexes. Food Hydrocoll. 80:195-205.

Chi, K., Catchmark, J.M. (2018b) Green Polymer Chemistry: New Products Processes, and Applications, Eds. Cheng, H. N., Gross, R. A., Smith, P. B. ACS Symposium Series. American Chemical Society, Washington DC, pp. 109-123.

Chivrac, F., Pollet, E., Avérous, L. (2009) Progress in nano-biocomposites based on polysaccharides and nanoclays. Mater. Sci. Eng., R Rep. 67(1):1-17.

Choudalakis, G., Gotsis, A.D. (2009) Permeability of polymer/clay nanocomposites: A review. Eur. Polym. J. 45(4):967-984.

Cole, M., Lindeque, P., Halsband, C., Galloway, T.S. (2011) Microplastics as contaminants in the marine environment: $a$ review. Mar. Pollut. Bull. 62(12):2588-2597.

Coltelli, M.-B., Wild, F., Bugnicourt, E., Cinelli, P., Lindner, M., Schmid, M., Weckel, V., Müller, K., Rodriguez, P., Staebler, A., Rodríguez-Turienzo, L., Lazzeri, A. (2015) State of the art in the development and properties of protein-based films and coatings and their applicability to cellulose based products: An extensive review. Coatings 6(1):1.

de Azeredo, H.M.C. (2009) Nanocomposites for food packaging applications. Food Res. Int. 42(9):1240-1253.

de Azeredo, H.M.C., Rosa, M.F., Mattoso, L.H.C. (2017) Nanocellulose in bio-based food packaging applications. Ind. Crop. Prod. 97:664-671.

Decher, G. (1997) Fuzzy nanoassemblies: Toward layered polymeric multicomposites. Science 277:1232-1237.

Decher, G., Schlenoff, J.B. Multilayer Thin Films: Sequential 
Assembly of Nanocomposite Materials. Wiley-VCH, New York, NY, 2003.

Degan, T., Shinde, S.L. (2019) Waste-plastic processing provides global challenges and opportunities. Mater. Res. Soc. Bull. 44(6):436-437.

Delidovich, I., Hausoul, P.J., Deng, L., Pfutzenreuter, R., Rose, M., Palkovits, R. (2016) Alternative monomers based on lignocellulose and their use for polymer production. Chem. Rev. 116(3):1540-1599.

Din, M.I., Ghaffar, T., Najeeb, J., Hussain, Z., Khalid, R., Zahid, H. (2020) Potential perspectives of biodegradable plastics for food packaging application - review of properties and recent developments. Food Add. Contam. Part A 37(4):665-680.

Donhowe, I.G., Fennema, O.R. (1993) Water vapor and oxygen permeability of wax films. J. Am. Oil Chem. Soc. 70(9):867-873.

Dufresne, A. (2018) Cellulose nanomaterials as green nanoreinforcements for polymer nanocomposites. Philos. Trans. R. Soc. Lond. Ser. A, Math. Phys. Sci. 376:2112.

Dufresne, A., Thomas, S., Pothan, L.A. Biopolymer Nanocomposites: Processing, Properties, and Applications. Springer, John Wiley \& Sons, Inc., Hoboken, New Jersey, 2013.

Duncan, T.V. (2011) Applications of nanotechnology in food packaging and food safety: barrier materials, antimicrobials and sensors. J. Colloid Interface Sci. 363(1):1-24.

Duncan, T.V. (2015) Release of engineered nanomaterials from polymer nanocomposites: the effect of matrix degradation. ACS Appl. Mater. Interfaces 7(1):20-39.

Ede, J.D., Ong, K.J., Goergen, M., Rudie, A., Pomeroy-Carter, C.A., Shatkin, J.A. (2019) Risk analysis of cellulose nanomaterials by inhalation: Current state of science. Nanomaterials 9:337.

Elsabee, M.Z., Abdou, E.S. (2013) Chitosan based edible films and coatings: a review. Mater. Sci. Eng. C 33(4):1819-1841.

Emadian, S.M., Onay, T.T., Demirel, B. (2017) Biodegradation of bioplastics in natural environments. Waste Manag. 59:526-536.

Espitia, P.J.P., Du, W.-X., Avena-Bustillos, R. d. J., Soares, N.d.F.F., McHugh, T.H. (2014) Edible films from pectin: Physical-mechanical and antimicrobial properties - a review. Food Hydrocoll. 35:287-296.

Fares, H.M., Schlenoff, J.B. (2017) Equilibrium overcompensation in polyelectrolyte complexes. Macromolecules 50(10):3968-3978.

Farris, S., Schaich, K.M., Liu, L., Piergiovanni, L., Yam, K.L. (2009) Development of polyion-complex hydrogels as an alternative approach for the production of bio-based polymers for food packaging applications: a review. Trends Food Sci. Technol. 20(8):316-332.

Ferreira, F.V., Cividanes, L.S., Gouveia, R.F., Lona, L.M.F. (2019) An overview on properties and applications of poly(butylene adipate-co-terephthalate)-PBAT based composites. Polym. Eng. Sci. 59(s2):E7-E15.

Ferrer, A., Pal, L., Hubbe, M. (2017) Nanocellulose in packaging: Advances in barrier layer technologies. Ind. Crop. Prod. 95:574-582.

Foster, E.J., Moon, R.J., Agarwal, U.P., Bortner, M.J., Bras, J., Camarero Espinosa, S., Chan, K.J., Clift, M.J.D., Cranston, E.D., Eichhorn, S.J., Fox, D.M., Hamad, W.Y., Heux, L., Jean, B., Korey, M., Nieh, W., Ong, K.J., Reid, M.S., Renneckar, S., Roberts, R., Shatkin, J.A., Simonsen, J., Stinson-Bagby, K., Wanasekara, N., Youngblood, J. (2018) Current characterization methods for cellulose nanomaterials. Chem. Soc. Rev. 47:2511-3006.

Fujisawa, S., Okita, Y., Fukuzumi, H., Saito, T., Isogai, A. (2011) Preparation and characterization of TEMPO-oxidized cellulose nanofibril films with free carboxyl groups. Carbohydr. Polym. 84(1):579-583.

Fukuzumi, H., Saito, T., Iwamoto, S., Kumamoto, Y., Ohdaira, T., Suzuki, R., Isogai, A. (2011) Pore size distribution of TEMPO-oxidized cellulose nanofibril films by positron annihilation lifetime spectroscopy. Biomacromolecules 12:4057-4062.

Galbis, J.A., Garcia-Martin Mde, G., de Paz, M.V., Galbis, E. (2016) Synthetic polymers from sugar-based monomers. Chem. Rev. 116(3):1600-1636.

Gandini, A., Lacerda, T.M., Carvalho, A.J., Trovatti, E. (2016) Progress of polymers from renewable resources: furans, vegetable oils, and polysaccharides. Chem. Rev. 116(3):1637-1669.

Garlotta, D. (2002) A literature review of poly(lactic acid). J. Polym. Environ. 9(2):63-84.

Genovese, L., Lotti, N., Gazzano, M., Siracusa, V., Dalla Rosa, M., Munari, A. (2016) Novel biodegradable aliphatic copolyesters based on poly(butylene succinate) containing thioether-linkages for sustainable food packaging applications. Polym. Degrad. Stab. 132:191-201.

Ghadermazi, R., Hamdipour, S., Sadeghi, K., Ghadermazi, R., Khosrowshahi Asl, A. (2019) Effect of various additives on the properties of the films and coatings derived from hydroxypropyl methylcellulose - A review. Food Sci. Nutr. 7(11):3363-3377.

Ghanbarzadeh, B., Oleyaei, S.A., Almasi, H. (2015) Nanostructured materials utilized in biopolymer-based plastics for food packaging applications. Crit. Rev. Food Sci. Nutr. 55(12):1699-1723.

Giannelis, E.P., Krishnamoorti, R., Manias, E. (1999) In: Adv. in Polym. Sci. Ed. Granick, S. Springer. pp. 107-148.

Gigli, M., Fabbri, M., Lotti, N., Gamberini, R., Rimini, B., Munari, A. (2016) Poly(butylene succinate)-based polyesters for biomedical applications: A review. Eur. Polym. J. 75:431-460.

Guillard, V., Gaucel, S., Fornaciari, C., Angellier-Coussy, H., Buche, P., Gontard, N. (2018) The next generation of sustainable food packaging to preserve our environment in a circular economy context. Front. Nutr. 5:121

Haas, K.-H., Amberg-Schwab, S., Rose, K., Schottner, G. (1999) Functionalized coatings based on inorganic-organic polymers (ORMOCERS) and their combination with vapor deposited inorganic thin films. Surf. Coat. Technol. 111:72-79.

Helanto, K., Martikainen, L., Talja, R., Rojas, O.J. (2019) Bio-based polymers for sustainable packaging and biobarriers: A critical review. BioResources 14(2):4902-4951.

Herrick, F.W., Casebier, R.L., Hamilton, J.K., Sandberg, K.R. (1983) Microfibrillated cellulose: morphology and accessibility. J. Appl. Polym. Sci., Appl. Polym. Symp. 37:797-813.

Hong, M., Chen, E.Y.X. (2017) Chemically recyclable polymers: a circular economy approach to sustainability. Green Chem. 19(16):3692-3706.

Horton, A.A., Walton, A., Spurgeon, D.J., Lahive, E., Svendsen, C. (2017) Microplastics in freshwater and terrestrial environments: Evaluating the current understanding to identify the knowledge gaps and future research priorities. Sci. Total Environ. 586:127-141.

Hubbe, M.A., Ferrer, A., Tyagi, P., Yin, Y., Salas, C., Pal, L., Rojas, 
J. (2017) Nanocellulose in thin films, coatings, and plies for packaging applications. BioResources 12(1):2143-2233.

Hult, E.-L., lotti, M., Lenes, M. (2010) Efficient approach to high barrier packaging using microfibrillar cellulose and shellac. Cellulose 17(3):575-586.

Ibn Yaich, A., Edlund, U., Albertsson, A.-C. (2015) Barriers from wood hydrolysate/quaternized cellulose polyelectrolyte complexes. Cellulose 22(3):1977-1991.

Iler, R.K. (1966) Multilayers of colloidal particles. J. Colloid Interface Sci. 21:569-594.

Isogai, A., Saito, T., Fukuzumi, H. (2011) TEMPO-oxidized cellulose nanofibers. Nanoscale 3(1):71-85.

Jambeck, J.R., Geyer, R., Wilcox, C., Siegler, T.R., Perryman, M., Andrady, R., Narayan, R., Law, K.L. (2015) Plastic waste inputs from land into the ocean. Science 347(6223):768-771.

Janjarasskul, T., Krochta, J.M. (2010) Edible packaging materials. Annu. Rev. Food Sci. Technol. 1:415-448.

Jiménez, A., Fabra, M.J., Talens, P., Chiralt, A. (2012) Edible and biodegradable starch films: A review. Food Bioprocess Technol. 5(6):2058-2076.

Kale, G., Kijchavengkul, T., Auras, R., Rubino, M., Seike, S.E., Singh, S.P. (2007) Compostability of bioplastic packaging materials: An overview. Macromol. Biosci. 7:255-277.

Kester, J.J., Fennema, O.R. (1986) Edible films and coatings: A review. J. Food Technol. 40(12):47-59.

Khwaldia, K., Arab-Therany, E., Desobry, S. (2010) Biopolymer coatings on paper packaging materials. Compr. Rev. Food Sci. Food Saf. 9:82-91.

Klemm, D., Kramer, F., Moritz, S., Lindström, T., Ankerfors, M., Gray, D., Dorris, A. (2011) Nanocelluloses: A new family of nature-based materials. Angew. Chem., Int. Ed. Engl. 50(24):5438-5466.

Kojima, Y., Usuki, A., Kawasumi, M., Okada, A., Fukushima, Y., Kurauchi, T., Kamigaito, O. (1993) Mechanical properties of nylon 6-clay hybrid. J. Mater. Res. 8(5):1185-1189.

Koros, W.J. (1990) Barrier polymers and structures: Overview. ACS Symp. Ser. 423:1-21.

Krochta, J.M. In: Handbook of Food Engineering. Eds. Heldman, D.R., Lund, D.B., Sabliov, C. CRC Press, Boca Raton, 2006. p. 847.

Kumar, A.P., Depan, D., Singh Tomer, N., Singh, R.P. (2009) Nanoscale particles for polymer degradation and stabilization - trends and future perspectives. Prog. Polym. Sci. 34(6):479-515.

Kuswandi, B. (2017) Environmental friendly food nano-packaging. Environ. Chem. Lett. 15(2):205-221.

Lagarón, J.M., Catala, R., Gavara, R. (2004) Structural characteristics defining high barrier properties in polymeric materials. Mater. Sci. Technol. 20:1-7.

Lagarón, J.M., López-Rubio, A., José Fabra, M. (2016) Bio-based packaging. J. Appl. Polym. Sci. 133(2):42165. (1 of 11).

Lange, J., Wyser, Y. (2003) Recent innovations in barrier technologies for plastic packaging - a review. Packag. Technol. Sci. 16(4):149-158.

Lavoine, N., Desloges, I., Dufresne, A., Bras, J. (2012) Microfibrillated cellulose - its barrier properties and applications in cellulosic materials: a review. Carbohydr. Polym. 90(2):735-764.

Lavoine, N., Desloges, I., Khelifi, B., Bras, J. (2014) Impact of different coating processes of microfibrillated cellulose on the mechanical and barrier properties of paper. J. Mater. Sci.
49(7):2879-2893.

Lefort, M., Popa, G., Seyrek, E., Szamocki, R., Felix, O., Hemmerle, J., Vidal, L., Voegel, J.C., Boulmedais, F., Decher, G., Schaaf, P. (2010) Spray-on organic/inorganic films: a general method for the formation of functional nano- to microscale coatings. Angew. Chem., Int. Ed. Engl. 49(52):10110-10113.

Leja, K., Lewandowicz, G. (2010) Polymer biodegradation and biodegradable polymers - a review. Pol. J. Environ. Stud. 19(2):255-266.

Li, Z., Olah, A., Baer, E. (2020) Micro- and nano-layered processing of new polymeric systems. Prog. Polym. Sci. 102:101210.

MacArthur, E., McKinsey. The New Plastic Economy: Rethinking the Future of Plastic \& Catalyzing Action. Ellen MacArthur Foundation and McKinsey, 2017.

MacArthur, E., McKinsey. Reuse-Rethinking Packaging, World Economic Forum. Ellen MacArthur Foundation and McKinsey, 2019.

McKeown, P., Roman-Ramirez, L.A., Bates, S., Wood, J., Jones, M.D. (2019) Zinc complexes for PLA formation and chemical recycling: towards a circular economy. ChemSusChem 12(24):5233-5238.

Miller, K.S., Krochta, J.M. (1997) Oxygen and aroma barrier properties of edible films: A review. Trends Food Sci. Technol. 8:228-238.

Min, K., Cuiffi, J.D., Mathers, R.T. (2020) Ranking environmental degradation trends of plastic marine debris based on physical properties and molecular structure. Nat. Commun. 1:1-11.

Minelli, M., Baschetti, M.G., Doghieri, F., Ankerfors, M., Lindström, T., Siro, I., Plackett, D. (2010) Investigation of mass transport properties of microfibrillated cellulose (MFC) films. J. Membr. Sci. 358:67-75.

Moon, R.J., Martini, A., Nairn, J., Simonsen, J., Youngblood, J. (2011) Cellulose nanomaterials review: structure, properties and nanocomposites. Chem. Soc. Rev. 401:3941-3994.

Narancic, T., O’Connor, K.E. (2019) Plastic waste as a global challenge: are biodegradable plastics the answer to the plastic waste problem? Microbiology 165(2):129-137.

Narancic, T., Verstichel, S., Reddy Chaganti, S., Morales-Gamez, L., Kenny, S.T., De Wilde, B., Babu Padamati, R., O’Connor, K.E. (2018) Biodegradable plastic blends create new possibilities for end-of-life management of plastics but they are not a panacea for plastic pollution. Environ. Sci. Technol. 52(18):10441-10452.

Nesic, A., Cabrera-Barjas, G., Dimitrijevic-Brankovic, S., Davidovic, S., Radovanovic, N., Delattre, C. (2019) Prospect of polysaccharide-based materials as advanced food packaging. Molecules 25(1):135.

Nielsen, L.E. (1967) Models for the permeability of filled polymer systems. J. Macromol. Sci. Part A, Chem. 1(5):929-942.

Paunonen, S. (2013) Strength and barrier enhancements of composites and packaging boards by nanocelluloses $-\mathrm{A}$ literature review. Nord. Pulp Pap. Res. J. 28(2):165-181.

Payne, J., McKeown, P., Jones, M.D. (2019) A circular economy approach to plastic waste. Polym. Degrad. Stab. 165:170-181.

Peelman, N., Ragaert, P., De Meulenaer, B., Adons, D., Peeters, R., Cardon, L., Van Impe, F., Devlieghere, F. (2013) Application of bioplastics for food packaging. Trends Food Sci. Technol. 32(2):128-141.

Petersen, K., Nielsen, P.V., Bertelsen, G., Lawther, M., Olsen, M.B., Nilsson, N.H., Mortensen, G. (1999) Potential of biobased 
materials in food packaging. Trends Food Sci. Technol. 10:52-68.

Ponting, M., Hiltner, A., Baer, E. (2010) Polymer nanostructures by forced assembly: Process, structure, and properties. Macromol. Symp. 294(1):19-32.

Porcel, C.H., Izquierdo, A., Ball, V., Decher, G., Voegel, J.-C., Schaaf, P. (2005) Ultrathin coatings and (poly(glutamic acid)/polyallylamine) films deposited by continuous and simultaneous spraying. Langmuir 21:800-802.

Priolo, M.A., Gamboa, D., Holder, K.M., Grunlan, J.C. (2010) Super gas barrier of transparent polymer-clay multilayer ultrathin films. Nano Lett. 10(12):4970-4974.

Qin, S., Pour, M.G., Lazar, S., Köklükaya, O., Gerringer, J., Song, Y., Wågberg, L., Grunlan, J.C. (2019a) Super gas barrier and fire resistance of nanoplatelet/nanofibril multilayer thin films. Adv. Mater. Interfaces 6(2):1801424.

Qin, S., Xiang, S., Eberle, B., Xie, K., Grunlan, J.C. (2019b) High moisture barrier with synergistic combination of $\mathrm{SiO}_{x}$ and polyelectrolyte nanolayers. Adv. Mater. Interfaces 6(16):1900740.

Rabnawaz, M., Wyman, I., Auras, R., Cheng, S. (2017) A roadmap towards green packaging: the current status and future outlook for polyesters in the packaging industry. Green Chem. 19(20):4737-4753.

Rastogi, V., Samyn, P. (2015) Bio-based coatings for paper applications. Coatings 5(4):887-930.

Ray, S.S., Yamada, K., Okamoto, M., Ueda, K. (2002) Polylactide-layered silicate nanocomposite: A novel biodegradable material. Nano Lett. 2:1093-1096.

Reddy, M.M., Vivekanandhan, S., Misra, M., Bhatia, S.K., Mohanthy, A.K. (2013) Biobased plastics and bionanocomposites: Current status and future opportunities. Prog. Polym. Sci. 38:1653-1689.

Rhim, J.-W., Park, H.-M., Ha, C.-S. (2013) Bio-nanocomposites for food packaging applications. Prog. Polym. Sci. 38(10-11):1629-1652.

Rhim, J.W., Ng, P.K. (2007) Natural biopolymer-based nanocomposite films for packaging applications. Crit. Rev. Food Sci. Nutr. 47(4):411-433.

Richardson, J.J., Bjornmalm, M., Caruso, F. (2015) Multilayer assembly. Technology-driven layer-by-layer assembly of nanofilms. Science 348(6233):aaa2491.

Robertson, G.L. Food Packaging. Principles and Practice, 2 Ed. CRC and Taylor \& Francis Group, Boca Raton, London, New York, 2006.

Robertson, G.L. Food Packaging and Shelf Life: A Practical Guide. CRC Press and Taylor \& Francis Group, Boca Raton, London, New York, 2009.

Rossi, M., Passeri, D., Sinibaldi, A., Angjellari, M., Tamburri, E., Sorbo, A., Carata, E., Dini, L. (2017) Nanotechnology for food packaging and food quality assessment. Adv. Food. Nutr. Res. 82:149-204.

Rovera, C., Ghaani, M., Farris, S. (2020) Nano-inspired oxygen barrier coatings for food packaging applications: An overview. Trends Food Sci. Technol. 97:210-220.

Rujnić-Sokele, M., Pilipović, A. (2017) Challenges and opportunities of biodegradable plastics: A mini review. Waste Manag. Res. 35(2):132-140.

Samori, C., Abbondanzi, F., Galletti, P., Giorgini, L., Mazzocchetti, L., Torri, C., Tagliavini, E. (2015) Extraction of polyhydroxyalkanoates from mixed microbial cultures: Impact on polymer quality and recovery. Bioresour. Technol. 189:195-202.

Sanchez, C., Belleville, P., Popall, M., Nicole, L. (2011) Applications of advanced hybrid organic-inorganic nanomaterials: from laboratory to market. Chem. Soc. Rev. 40:696-753.

Scaffaro, R., Botta, L., Lopresti, F., Maio, A., Sutera, F. (2016) Polysaccharide nanocrystals as fillers for PLA based nanocomposites. Cellulose 24(2):447-478.

Scaffaro, R., Maio, A., Sutera, F., Gulino, E.F., Morreale, M. (2019) Degradation and recycling of films based on biodegradable polymers: A short review. Polymers 11(4):651.

Schneiderman, D.K., Hillmyer, M.A. (2017) 50th anniversary perspective: There is a great future in sustainable polymers. Macromolecules 50(10):3733-3749.

Senturk Parreidt, T., Muller, K., Schmid, M. (2018) Alginate-based edible films and coatings for food packaging applications. Foods 7(10): 170 .

Shatkin, J.A. (2020) The future in nanosafety. Nano Lett. 20(3):1479-1480.

Shatkin, J.A., Kim, B. (2015) Cellulose nanomaterials: life cycle risk assessment, and environmental health and safety roadmap. Environ. Sci. Nano 2(5):477-499.

Shimizu, M., Saito, T., Isogai, A. (2016) Water-resistant and high oxygen-barrier nanocellulose films with interfibrillar cross-linkages formed through multivalent metal ions. J. Membr. Sci. 500:1-7.

Sinha Ray, S., Okamoto, M. (2003) Polymer/layered silicate nanocomposites: a review from preparation to processing. Prog. Polym. Sci. 28:1539-1641.

Sinha Ray, S.S., Yamada, K., Okamoto, M., Ueda, K. (2002) Polylactide-layered silicate nanocomposite: A novel biodegradable material. Nano Lett. 2(10):1093-1096.

Siró, I., Plackett, D. (2010) Microfibrillated cellulose and new nanocomposite materials: a review. Cellulose 17(3):459-494.

Smith, R.J., Long, C.T., Grunlan, J.C. (2018) Transparent polyelectrolyte complex. Thin films with ultralow oxygen transmission rate. Langmuir 34(37):11086-11091.

Song, Y., Gerringer, J., Qin, S., Grunlan, J.C. (2018) High oxygen barrier thin film from aqueous polymer/clay slurry. Ind. Eng. Chem. Res. 57(20):6904-6909.

Sorrentino, A., Gorrasi, G., Vittoria, V. (2007) Potential perspectives of bio-nanocomposites for food packaging applications. Trends Food Sci. Technol. 18(2):84-95.

Spence, K.L., Venditti, R.A., Rojas, O.J., Pawlak, J.J., Hubbe, M.A. (2011) Water vapor barrier properties of coated and filled microfibrillated cellulose composite films. BioResources 6(4):4370-4388.

Su, Y., Yang, B., Liu, J., Sun, B., Cao, C., Zou, X., Lutes, R., He, Z. (2018) Prospects for replacement of some plastics in packaging with lignocellulose materials: A brief review. BioResources 13(2):4550-4576.

Syverud, K., Stenius, P. (2009) Strength and barrier properties of MFC films. Cellulose 16(1):75-85.

Sæther, H.V., Holme, H.K., Maurstad, G., Smidsrød, O., Stokke, B.T. (2008) Polyelectrolyte complex formation using alginate and chitosan. Carbohydr. Polym. 74(4):813-821.

Tanaka, K., Watanuki, Y., Takada, H., Ishizuka, M., Yamashita, R., Kazama, M., Hiki, N., Kashiwada, F., Mizukawa, K., Mizukawa, H., Hyrenbach, D., Hester, M., Ikenaka, Y., Nakayama, S.M.M. 
(2020) In vivo accumulation of plastic-derived chemicals into seabird tissues. Curr. Biol. 30(4):723-728.

Tang, X.Z., Kumar, P., Alavi, S., Sandeep, K.P. (2012) Recent advances in biopolymers and biopolymer-based nanocomposites for food packaging materials. Crit. Rev. Food Sci. Nutr. 52(5):426-442.

Thakur, R., Pristijono, P., Scarlett, C.J., Bowyer, M., Singh, S.P., Vuong, Q.V. (2019) Starch-based films: Major factors affecting their properties. Int. J. Biol. Macromol. 132:1079-1089.

Thellen, C.T. High barrier multilayer packaging by the coextrusion method: The effect of nanocomposites and biodegradable polymers on flexible film properties. Univ. of Massachusetts, Lowell, Massachusetts, USA, 2010.

Turbak, A.F., Snyder, F.W., Sandberg, K.R. (1983) Microfibrillated cellulose, a new cellulose product: Properties, uses and commercial potential. J. Appl. Polym. Sci., Appl. Polym. Symp. 37:815-827.

Wagner, A., White, A.P., Stueckle, T.A., Banerjee, D., Sierros, K.A., Rojanasakul, Y., Agarwal, S., Gupta, R.K., Dinu, C.Z. (2017) Early assessment and correlations of nanoclay's toxicity to their physical and chemical properties. ACS Appl. Mater. Interfaces 9(37):32323-32335.

Wang, H., Qian, J., Ding, F. (2018) Emerging chitosan-based films for food packaging applications. J. Agric. Food Chem. 66(2):395-413.

Wang, J., Gardner, D.J., Stark, N.M., Bousfield, D.W., Tajvidi, M., Cai, Z. (2017) Moisture and oxygen barrier properties of cellulose nanomaterial-based films. ACS Sustain. Chem. Eng. 6(1):49-70.

Wei, R., Zimmermann, W. (2017) Microbial enzymes for the recycling of recalcitrant petroleum based plastics: How far are we? Microb. Biotechnol. 10:1308-1322.

Wyser, Y., Adams, M., Avella, M., Carlander, D., Garcia, L., Pieper, G., Rennen, M., Schuermans, J., Weiss, J. (2016) Outlook and challenges of nanotechnologies for food packaging. Packag. Technol. Sci. 29(12):615-648.

Xie, J., Zhang, K., Wu, J., Ren, G., Chen, H., Xu, J. (2016) Bio-nanocomposite films reinforced with organo-modified layered double hydroxides: Preparation, morphology and properties. Appl. Clay Sci. 126:72-80.
Xu, J., Guo, B.H. (2010) Poly(butylene succinate) and its copolymers: research, development and industrialization. Biotechnol. J. 5(11):1149-1163.

Yang, K.K., Wang, X.-L., Wang, Y.-Z. (2007) Progress in nanocomposite of biodegradable polymer. J. Ind. Eng. Chem. 13(4):485-500.

Yeo, B.G., Takada, H., Yamashita, R., Okazaki, Y., Uchida, K., Tokai, T., Tanaka, K., Trenholm, N. (2019) PCBs and PBDEs in microplastic particles and zooplankton in open water in the Pacific Ocean and around the coast of Japan. Mar. Pollut. Bull. 151:110806.

Yin, G.-Z., Yang, X.-M. (2020) Biodegradable polymers: a cure for the planet, but a long way to go. J. Polym. Res. 27(2):38.

Youssef, A.M., El-Sayed, S.M. (2018) Bionanocomposites materials for food packaging applications: Concepts and future outlook. Carbohydr. Polym. 193:19-27.

Yu, J., Ruengkajorn, K., Crivoi, D.G., Chen, C., Buffet, J.C., O'Hare, D. (2019) High gas barrier coating using non-toxic nanosheet dispersions for flexible food packaging film. Nat. Commun. 10(1):2398.

Zeng, S.H., Duan, P.P., Shen, M.X., Xue, Y.J., Wang, Z.Y. (2016) Preparation and degradation mechanisms of biodegradable polymer: a review. IOP Conf. Ser., Mater. Sci. Eng. 137:012003.

Zhang, X., Xu, Y., Zhang, X., Wu, H., Shen, J., Chen, R., Xiong, Y., Li, J., Guo, S. (2019) Progress on the layer-by-layer assembly of multilayered polymer composites: Strategy, structural control and applications. Prog. Polym. Sci. 89:76-107.

Zhao, P., Liu, W., Wu, Q., Ren, J. (2010) Preparation, mechanical, and thermal properties of biodegradable polyesters/poly (lactic acid) blends. J. Nanomater. 2010:1-8.

Zink, J., Wyrobnik, T., Prinz, T., Schmid, M. (2016) Physical, chemical and biochemical modifications of protein-based films and coatings: An extensive review. Int. J. Mol. Sci. 17(9):1376.

Zubair, M., Ullah, A. (2020) Recent advances in protein derived bionanocomposites for food packaging applications. Crit. Rev. Food Sci. Nutr. 60(3):406-434. 